\title{
الاستفادة هن بعض عناصر الفن الشعبي المصري \\ في إثراء المشغولة النسيجية باستخدام نظرية الفوضى
}

\author{
إعلاد \\ ه. رجب السيد سلامه

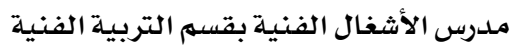 \\ كلية التربيـة النوعية - جامعة المنصورة

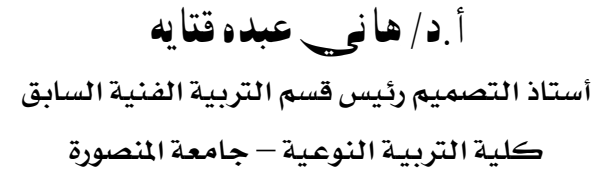

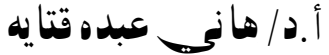 \\ كلية التربية النوعية - جامعة المنصورة

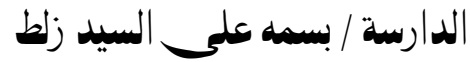

مدرس مساعد بقسم التربية الفنية

كلية التربيـة النوعية - جامعة المنصورة
}

مجلة بحوث التربية النوعية ـ جامعة المنصورة

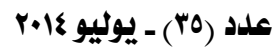

بحث مستل من رسالة دكتوراه 


\title{
الاستفادة هن بهض عناصر الفن الشعبي المصري

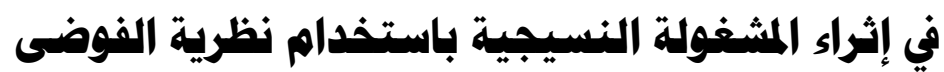

\author{
إعداد \\ $* *$

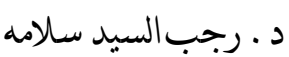

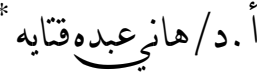 \\ الدارسة / بسمه علم السيد زلط
}

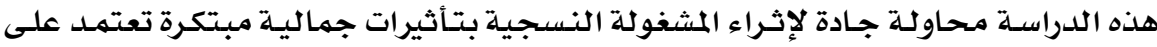

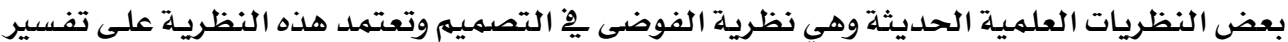

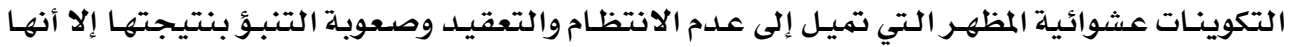

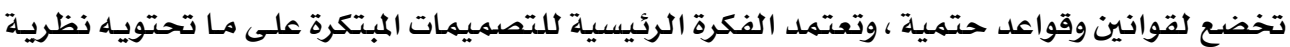

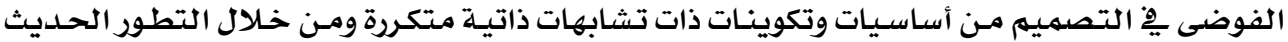

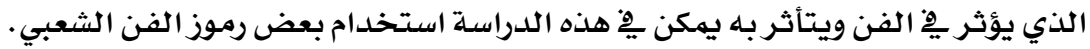

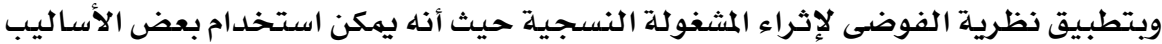

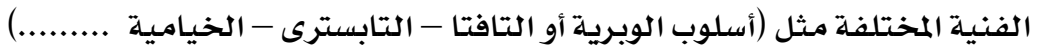

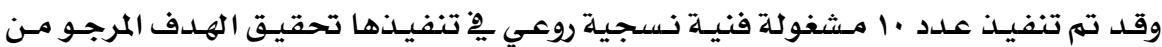

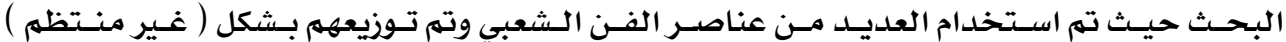

باستخدام نظرية الفوضي يْ التوزيع للحصول على شكل جمالي للمشغولية الفنية النسيجية.

الاقدهمة:

لكل شعب من الشعوب أصالته وتاريخه وفنونه الشعبية التي تميزه وتدل على بيئته وثقافته

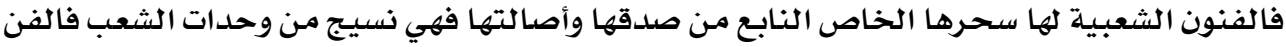

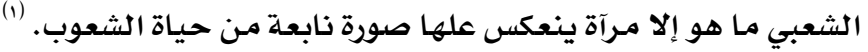

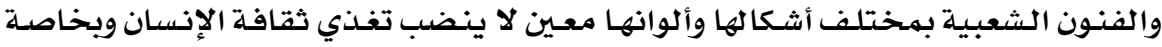

الفنان وتنعكس على فنه لأن الفن صورة منتقاة من الحياة أوضحها الفنان بنظرة على بيئته.

"أستاذ التصميهم رئيس قسم التربية الفنية السابق - كلية التربية النوعية - جامعة المنصـورة

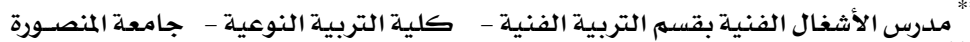

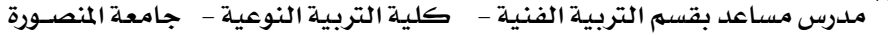

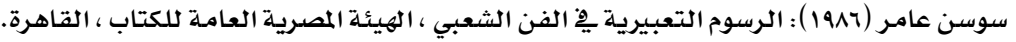


وتعتبر الفنون الشعبية المحصلة الفنية بين حياة الإنسان وعمله وبين الطبيعة وهي مرتبطـة

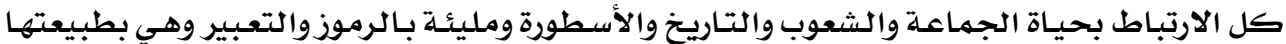

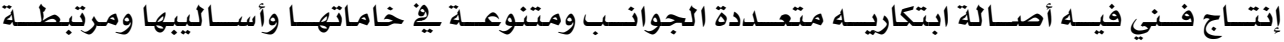

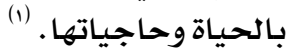

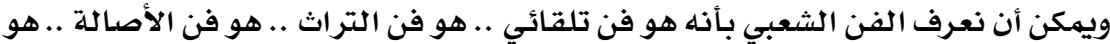

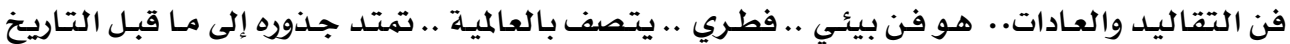

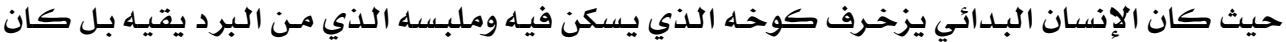

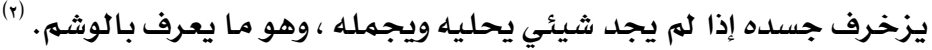
وهذه الدراسلة محاولة جادة لإثراء المشغولة النسجية بتأثيرات جماليـة مبتكرة تعتمـد على الفى

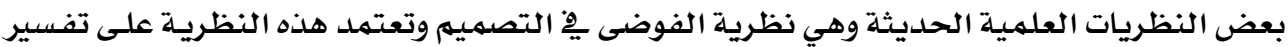

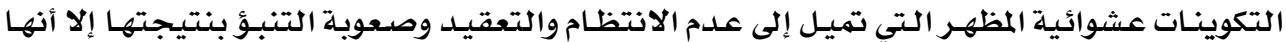

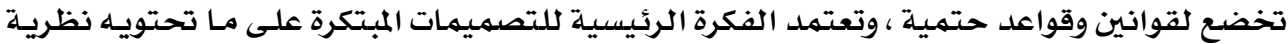

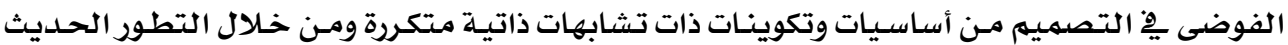
الذي يؤثر ٌِِ الفن ويتأثر به يمكن يِّ هله الدراسة استخدام بعض رموز الفن الشعبي

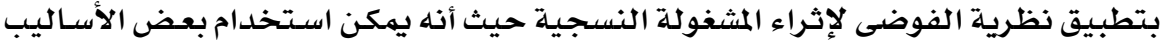

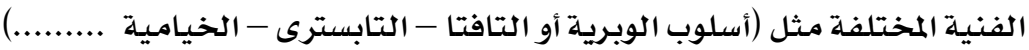
مشكلة البحث:

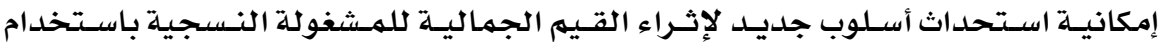

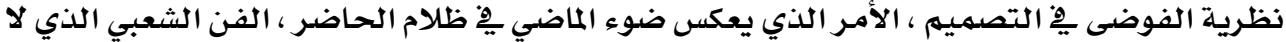

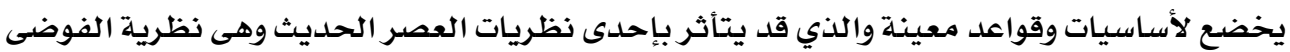

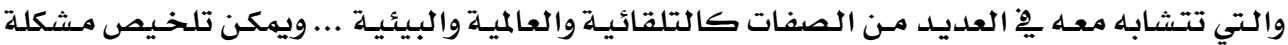

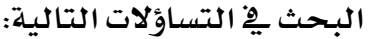

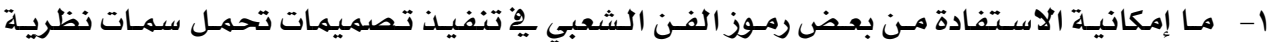

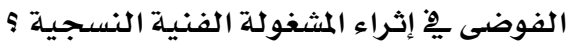

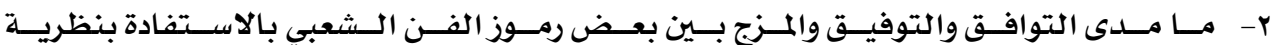
الفوضى المنظمة ؟

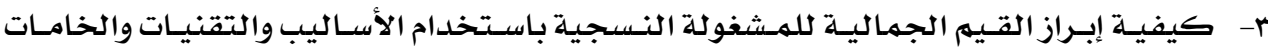

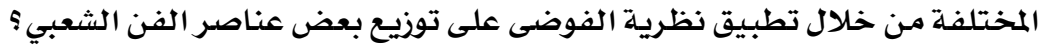

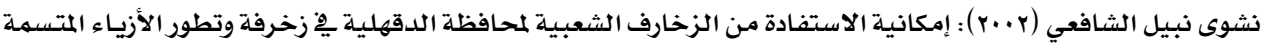
بالأصالة والمعاصرة للمرأة المصرية ، رسالة ماجستير غير منشورة ، كلية التربية النوعية ، جامعة المنصورة.

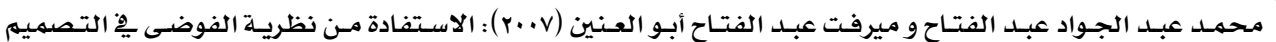
Korea-Egypt: International conference للحصول علس منسوجات ذات تأثيرات نسجية وجماليـة مبتكرة ، (fashion spirit). 


\section{أهد|ف البحث : يهدف البحث إلى:}

1- الوراسة العلاقة بين عناصر الفن الشعبي ونظرية الفوضى.

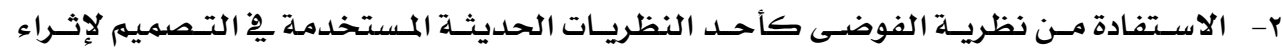

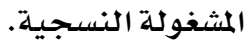

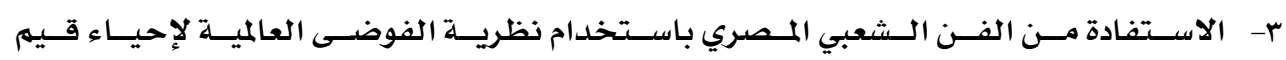

الأصالة والمعاصرة.

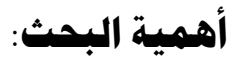

1- استحداث تصميمات تحمل الطابع الشعبي باستخدام نظريـة الفوضى.

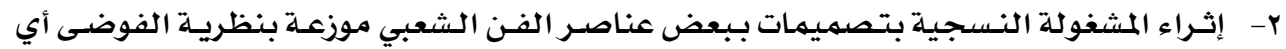

$$
\text { بطريقة غير تقليدية. }
$$

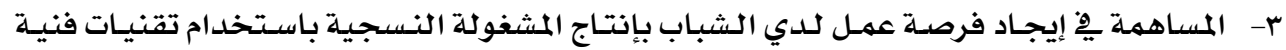

متتوعة يقبل عليها جمهور المستهلكين.

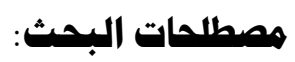

نظرية الفوضى (Chaos theory)

هي تصور الكون خاضعا لقـوانين حتهيـة ولكسن بأسـلوب يميـل إلى عـدم الانتظـام والتعقيــ

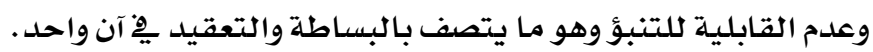

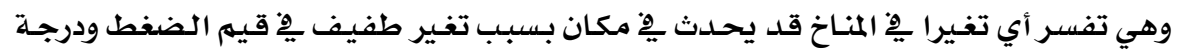

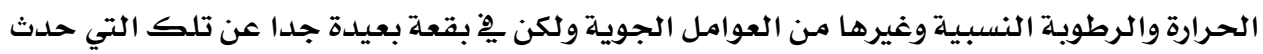

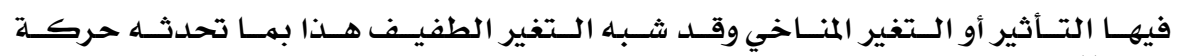

جناح الفراشـة.

الفز الشعبي: (Folklore or Folk art)

1- يعرف قاموس أكسفورد (Oxford) الفن الشعبي بأنه اصطلاح يصف الأثـياء والزخسارف

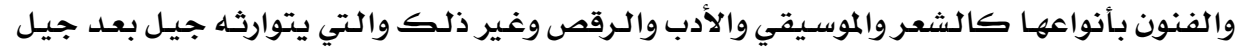

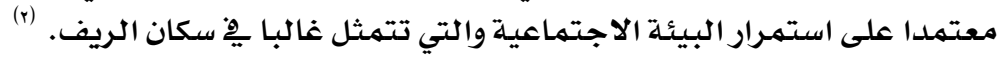

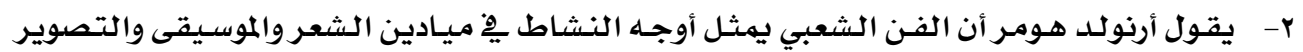

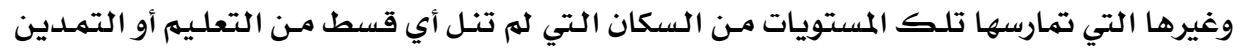

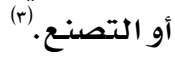

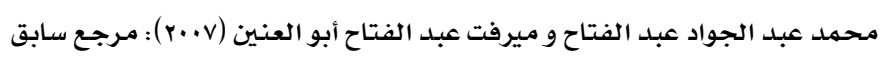

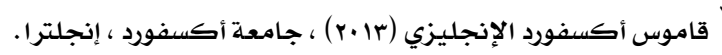

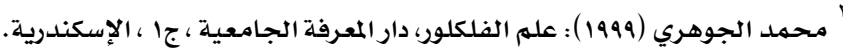




\section{(Folklore) (التراش الشعبي:}

هِّْ اللغــة العربيـة: الـتراث هـو القـيم الإنسـانية المتوارثـة أي مـا يخلفـه الرجـل لورثتـه جيـل

وكذلك هو كل مـا ينتقل مـن السلف إلى الخلف ِِّ كل جوانب الحيـاة الماديـة والمعنويـة

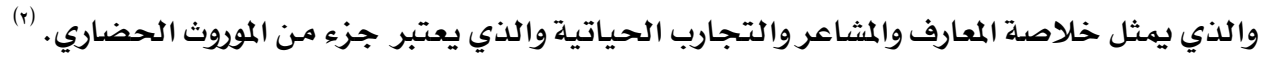

المشفولة النسجية: (Hand-made Weaving)

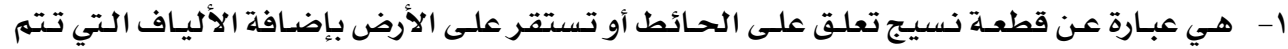

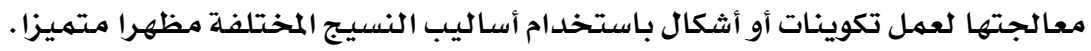

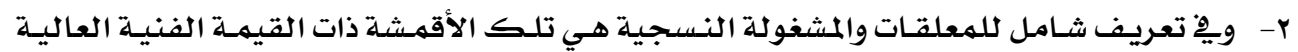

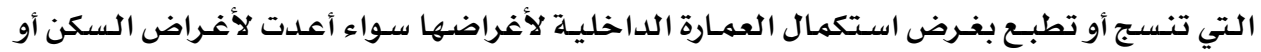

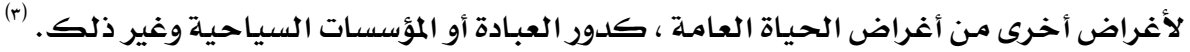

\section{الدراسات النظرية}

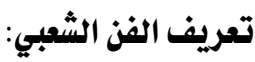

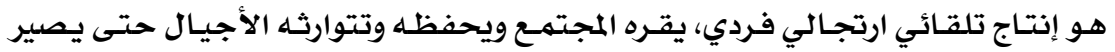

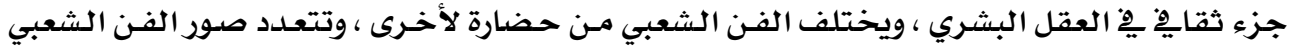

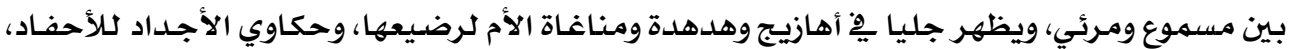

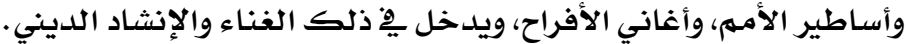

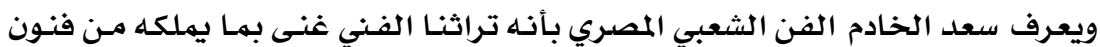

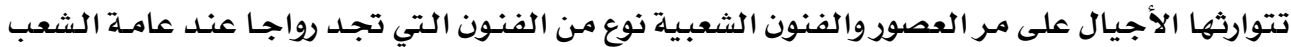

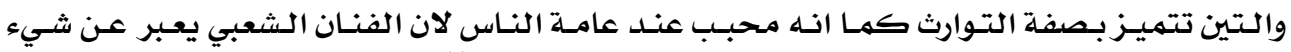

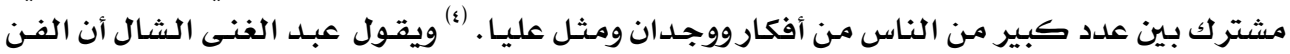

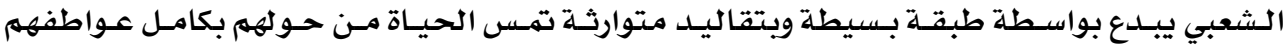

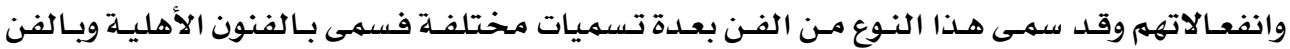

إبراهيه أنيس وآخرون (1910) : المعجم الوسيط ، مجمع اللغة العربية ، الجزء الأول ، الطبعة الثالثة.

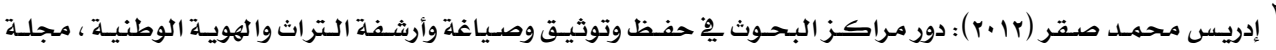
أمارياك ، الأكاديمية الأمريكية للعلوم والتكنولوجيا ، المجلد الثالث ، العدد الخامس.

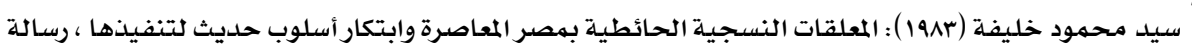
دكتوراه، كلية الفنون التطبيقية ، جامعة حلوان.

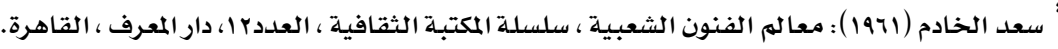


الريفـي وبـالفنون الإقليميــة وبـالفلكلور والمـأثورات الـشعبية وسمهـى بـالفن الـشعبي وأحيانـا بـالفن

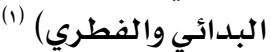

كما يتحدث هاني إبراهيه جابر عن الفن الشعبي فيقول إن التقاليد الاجتماعيـة هي أهـم

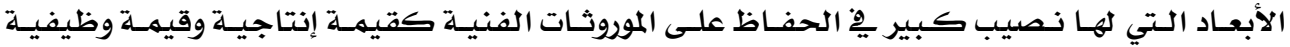

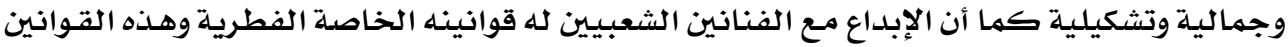

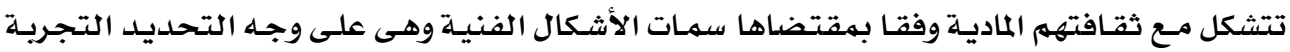

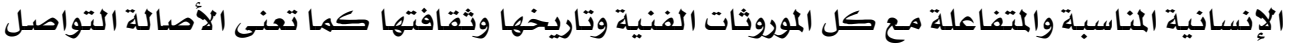

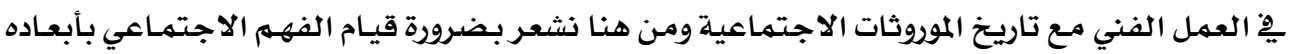

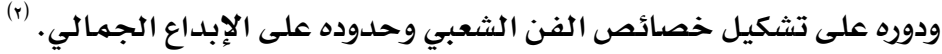

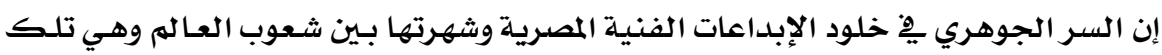

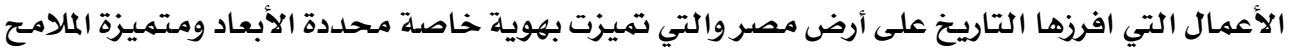

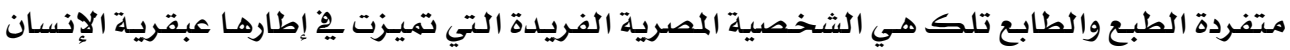

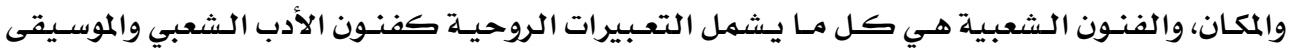

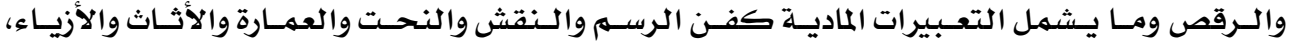

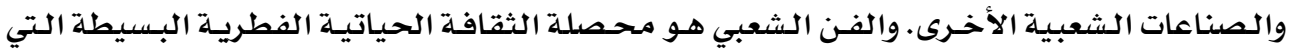

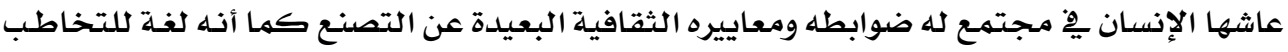

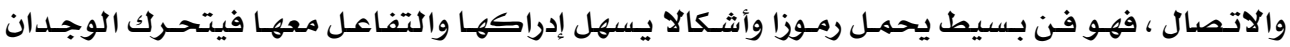

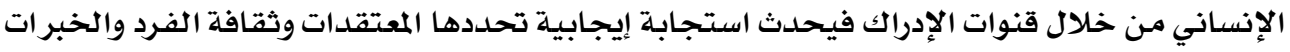

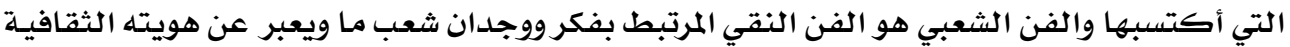

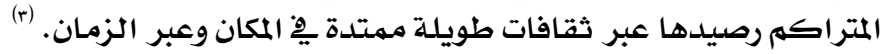
فالفن الشعبي فن نقسي وفطري ـ الذي يتصف بالتلقائيسة والعفويـة والبسساطة والتسطيح

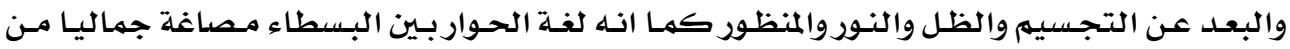

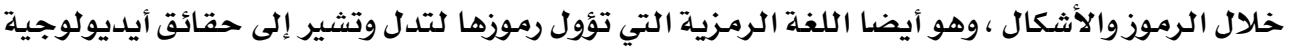

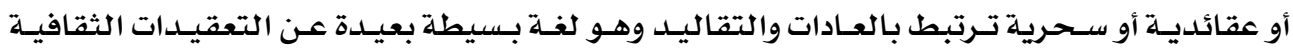

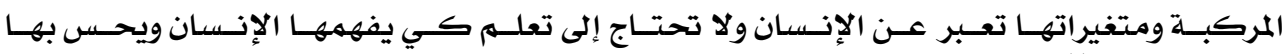

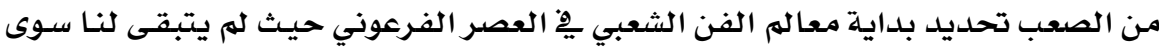

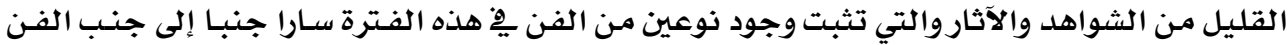

عبد الغنى الشال (1999) ): عروس المولد ، الهيئة العامـة لقصور الثقافة ، القاهرة. هاني إبراهيم جابر: (19VVV) الفنون الشعبية بين الواقع والمستقبل - الهيئة المصرية للكتاب - القاهرة.

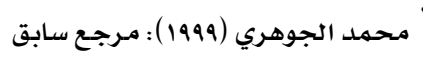
يوسف خليفة غراب ، نجوى حسين حجازي ( ... ب): الفن والأسطورة ، زهراء الشرق ، القاهرة. 


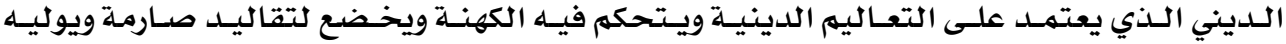

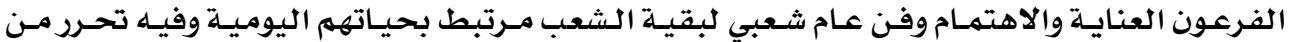

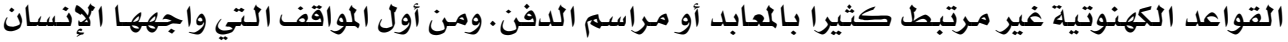

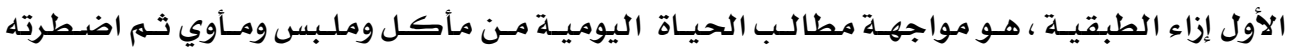

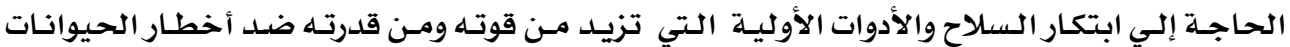

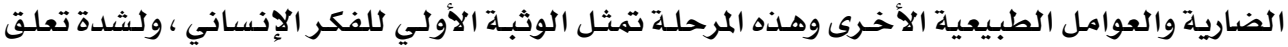

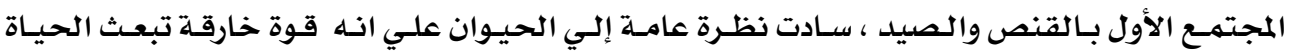

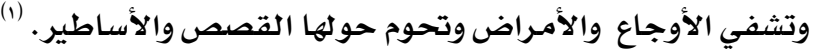
موضوعات الفن الشعبي

$$
\begin{aligned}
& \text { 1- التعبير عن المناسبة الدينية (الحجج - عيد الفطر- عيد الأضحى - النصف من شعبان) } \\
& \text { r- التعبير عن المناسبات الاجتماعية (الزواج - الطهور - أعياد الميلاد) } \\
& \text { r- ب التعبير عن المناسبات السياسية (الانتصار) } \\
& \text { ع- التعبير عن الباراسيكولوجية (الغيبيات - الجنة - النار - الموت - الخلود ......الخئ) }
\end{aligned}
$$

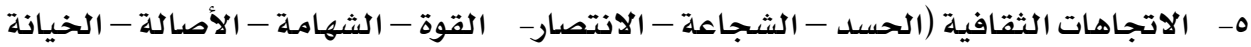

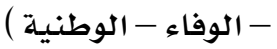

$$
\begin{aligned}
& \text { ج- الأسطورة (تجسيد الذات والإسقاطات النفسية) } \\
& \text { V- - الحكاية (التقمص والتوحد) } \\
& \text { ^- الرواية (تحقيق الذاتية والوجود داخل البناء السردي) }
\end{aligned}
$$

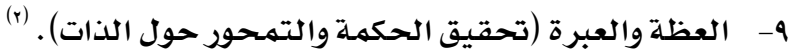

$$
\begin{aligned}
& \text { المعتقدات والعادات والتقاليد الشعبية }
\end{aligned}
$$

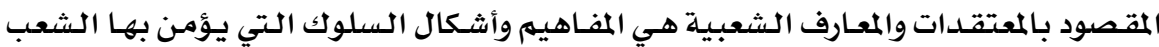

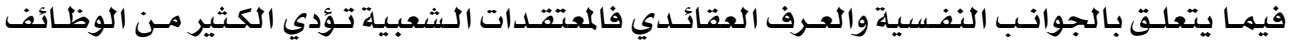

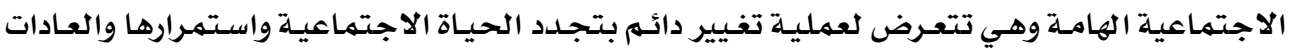

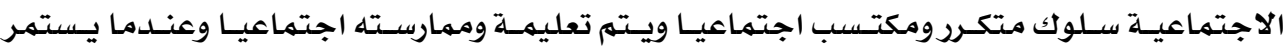

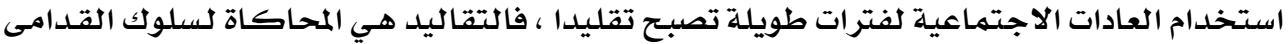

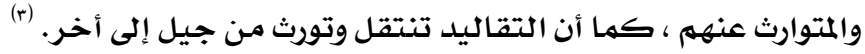

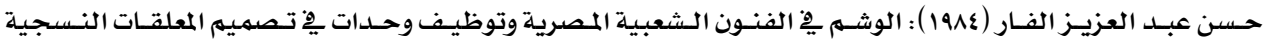
المطبوعة ، رسالة ماجستير غير منشورة ، كلية الفنون التطبيقية ، جامعة حلوان.

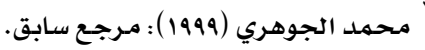
فوزي العنتيل (1999) ) : الفولكلور ما هو ،الهيئة العامـة لقصور الثقافة، مكتبـة الدراسات الشعبية ، القاهرة. 
الرمز في الفز الشعبي

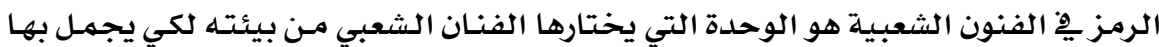

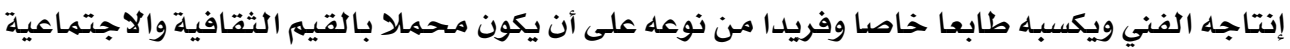

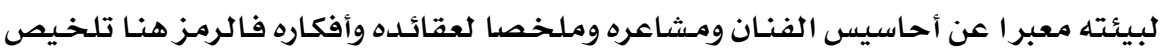

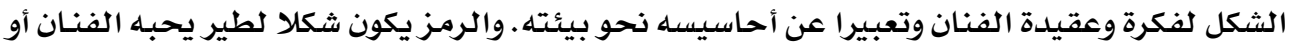

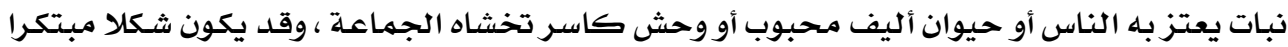

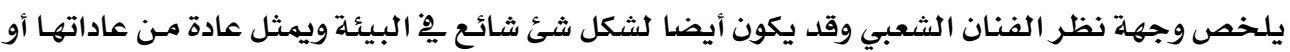

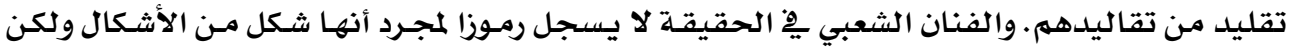

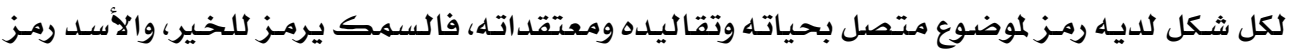

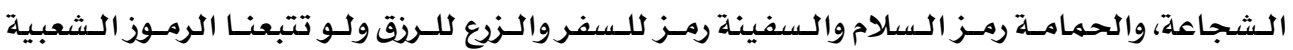

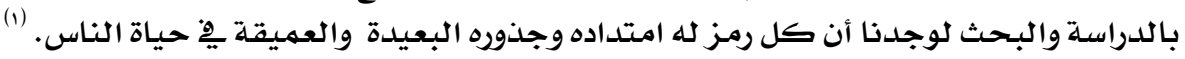

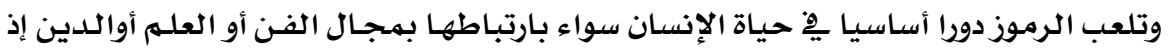

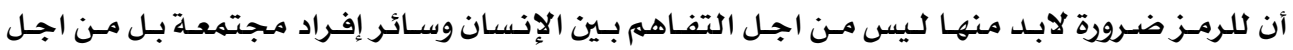

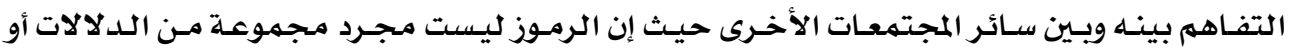

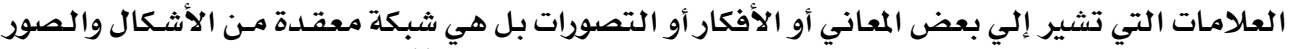

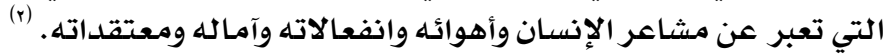
اللوز في الفز الشعبي

يلعب اللون دورا أساسياً يِّ الفنون الشعبية فتلك الفنـون تتميز بألوانها الفطريـة الأوليـة

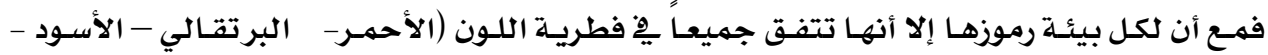

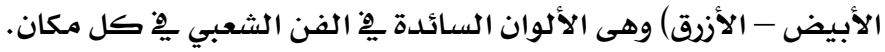

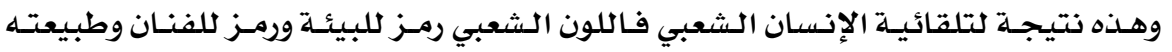

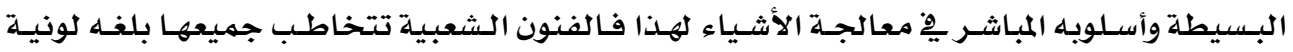

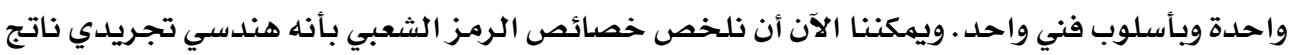

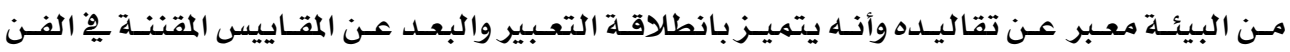

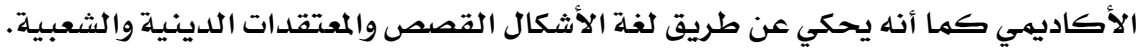

\section{السمات العامة للزخارف الشعبية وملدولاتها :}

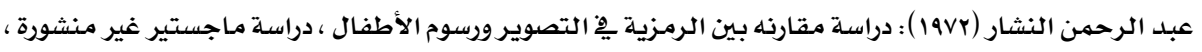
كلية التربية الفنية ، جامعة حلوان. حسين على الشريف (1970) : الرمز يِّ الفن الشعبي ، مجلة الفنون الشعبية ، العدد الثاني ، القاهرة. 


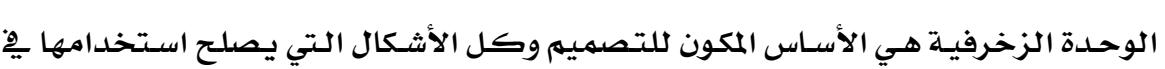

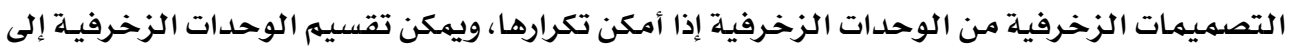
نوعين رئيسين :

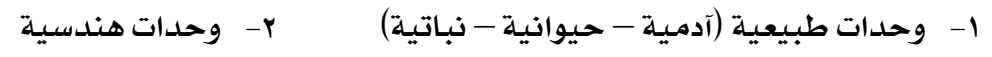

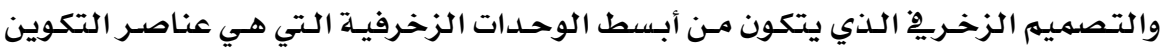

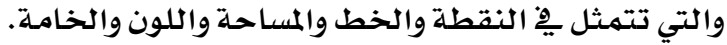

\section{وفيما يلي عرض وتصنيف لبعض أهم الوحدات الزخرفية ومدلولاتها :}

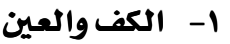

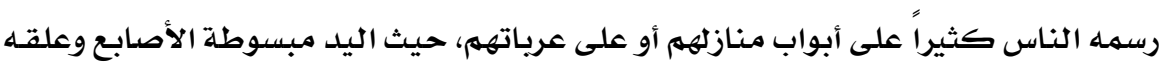

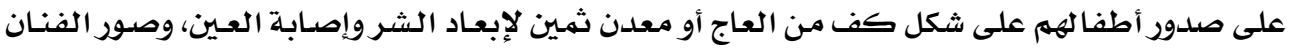

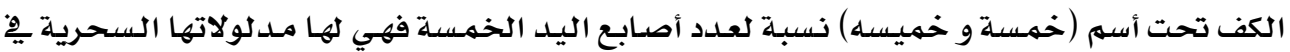

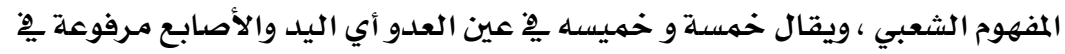

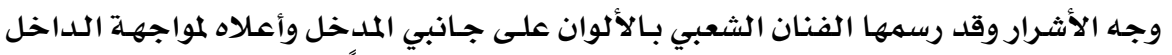

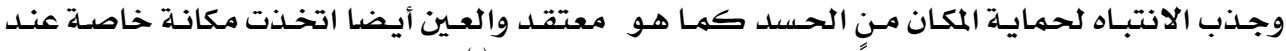

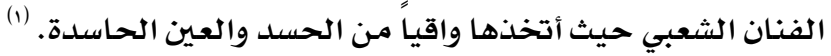

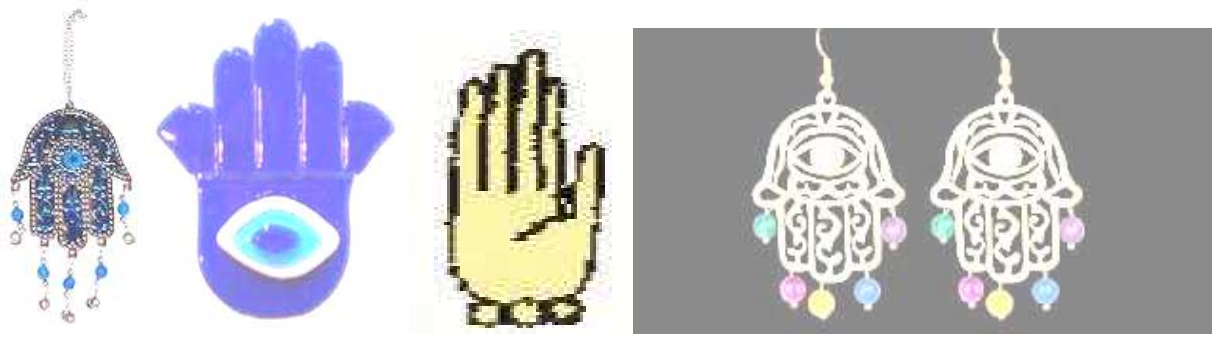

شكل (1)

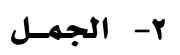

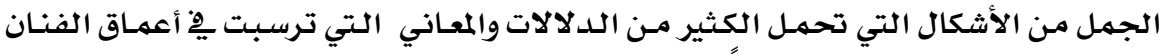

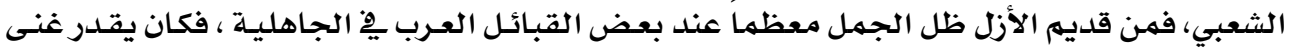

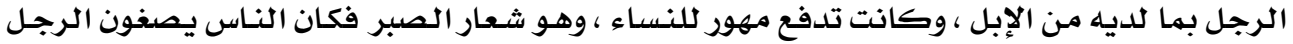

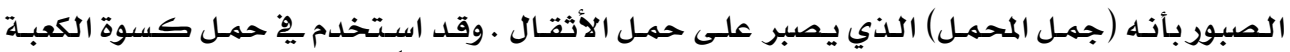

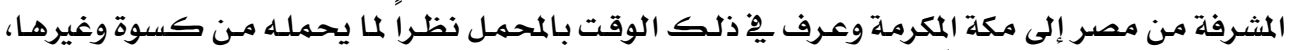

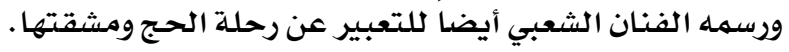




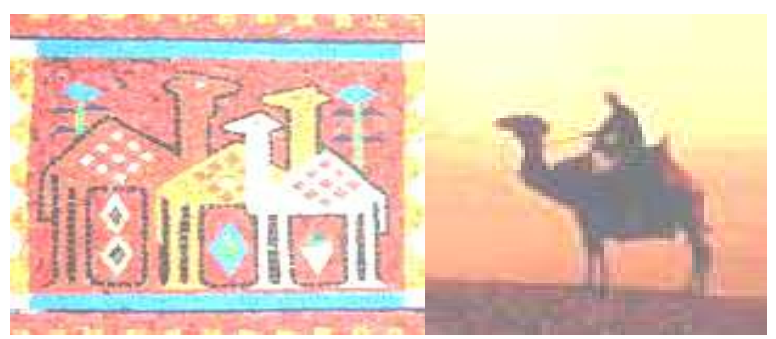

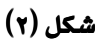

\section{r- r الحمـــــ}

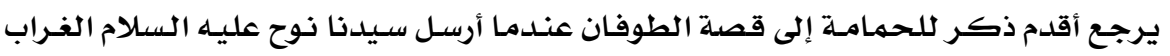

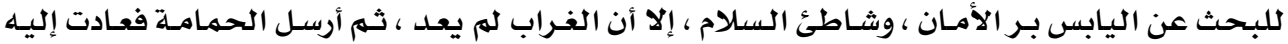

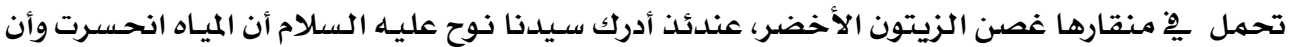

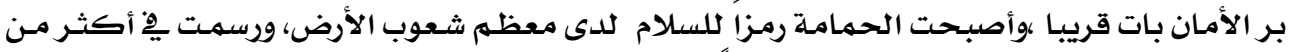

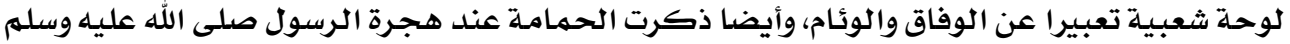

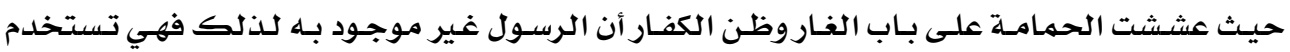

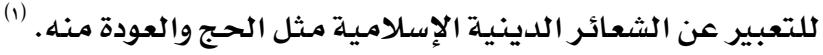
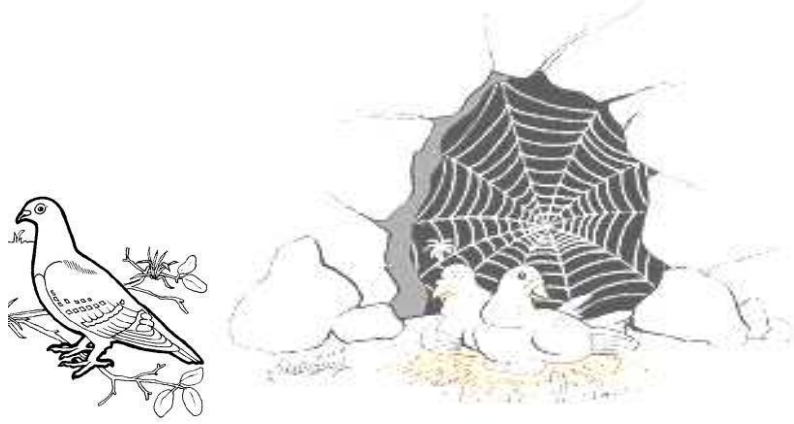

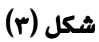

\section{ع- السمكة}

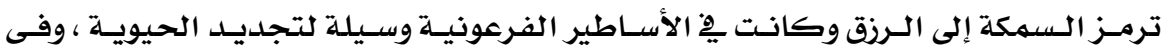

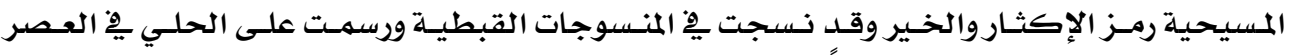

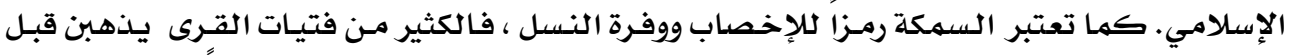

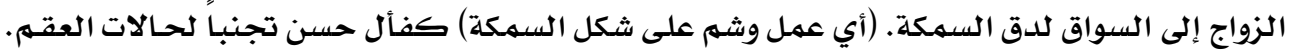

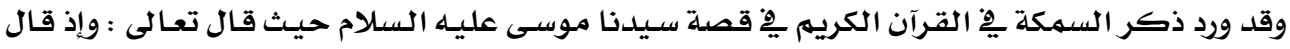

ثريا نصر (1991) : تاريخ أزياء الشعوب ، عالم الكتب ، القاهرة. 


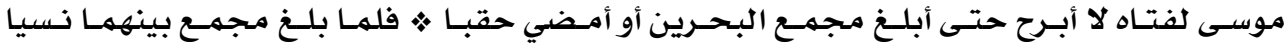

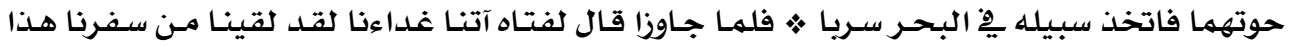

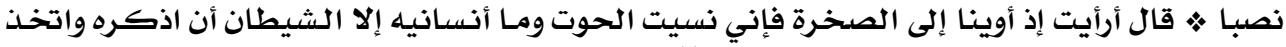

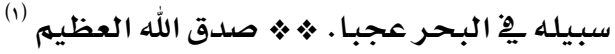
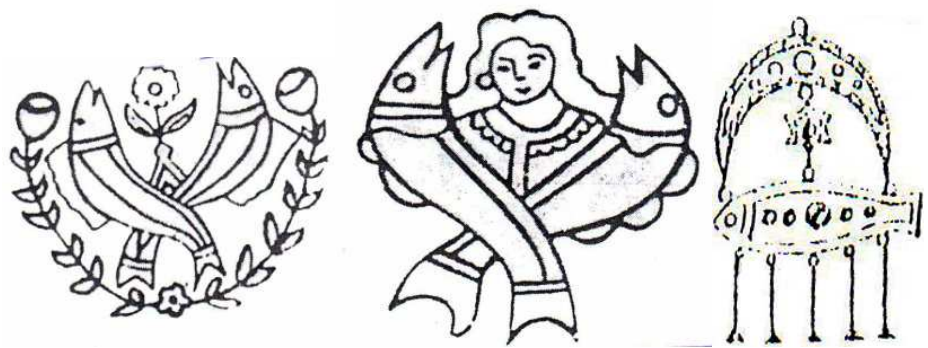

شكل (ع)

$$
\text { 0- الـعقـرب }
$$

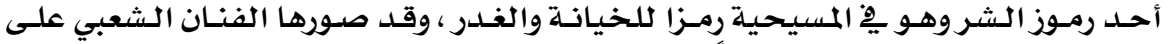

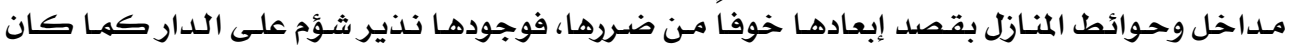

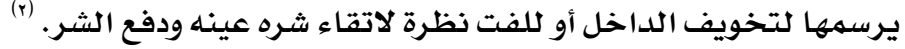
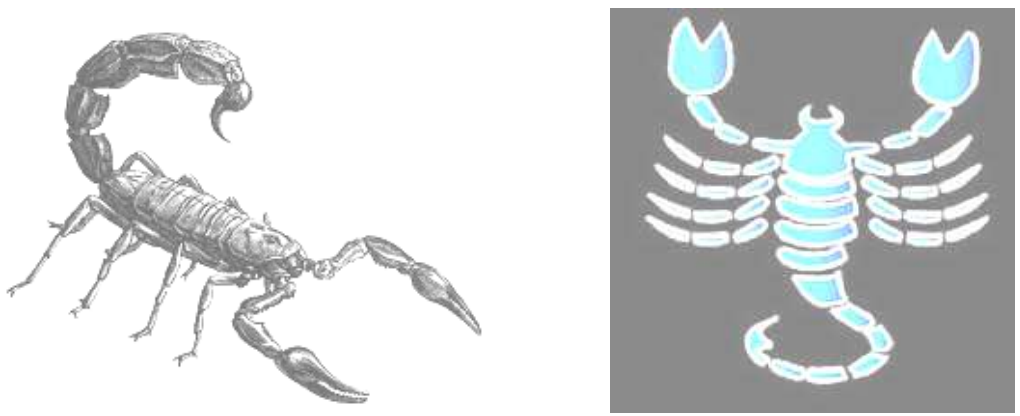

شكل (o)

7- السعصفور

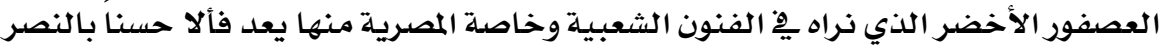

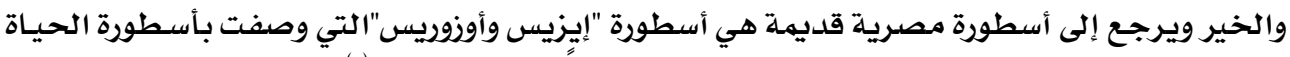

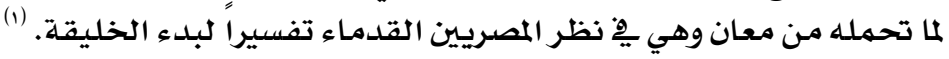

ثريا نصر (1991) ): مـرجـع سابق.

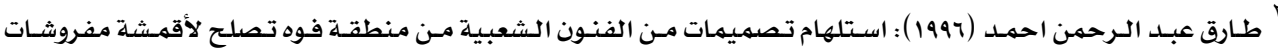

الأرضية ، رسالة ماجستير غير منشورة ، كلية الفنون التطبيقية ، جامعة حلوان. 

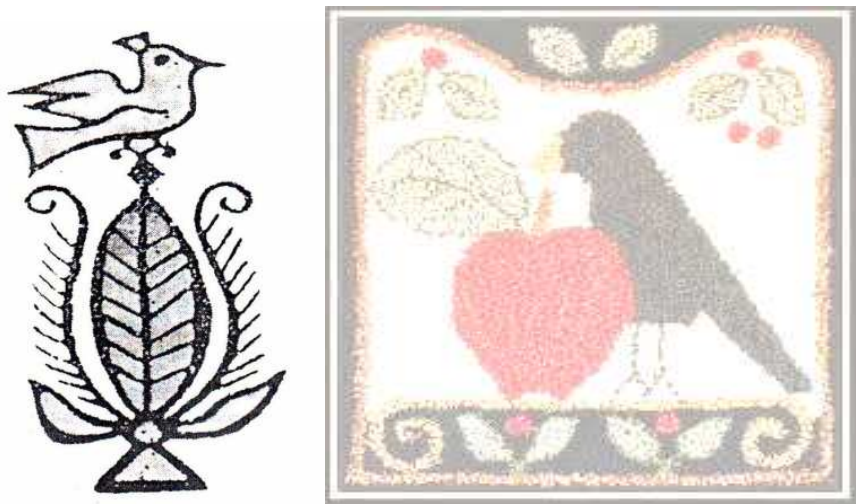

شكل (ף)

- - V

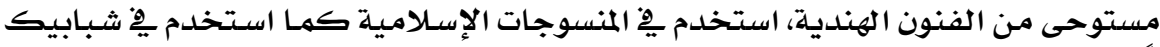

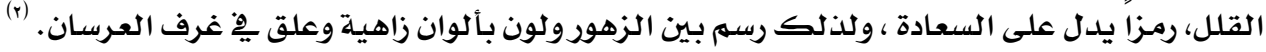
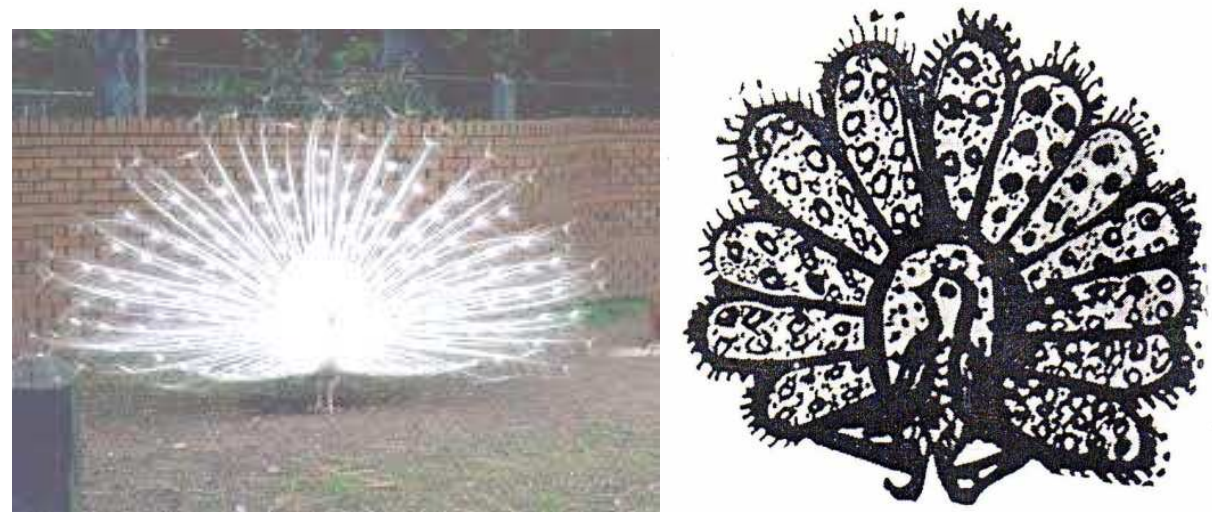

شكل (v)

-

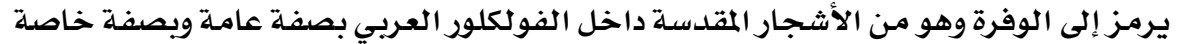

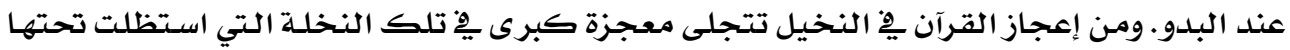

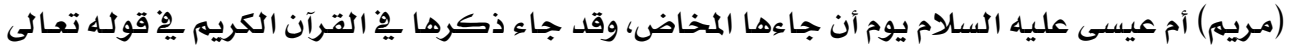

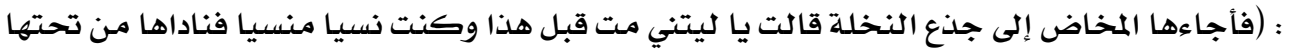

ثريا نصر (1991) ) مرجع سابق

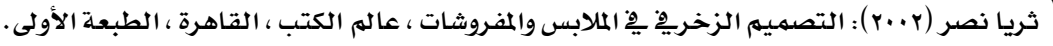




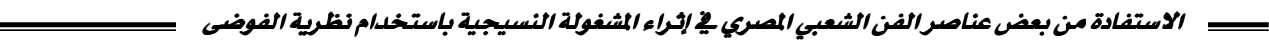

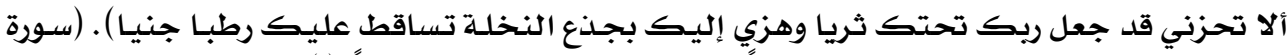

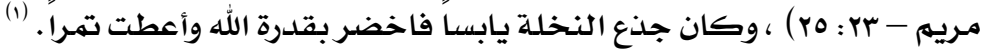

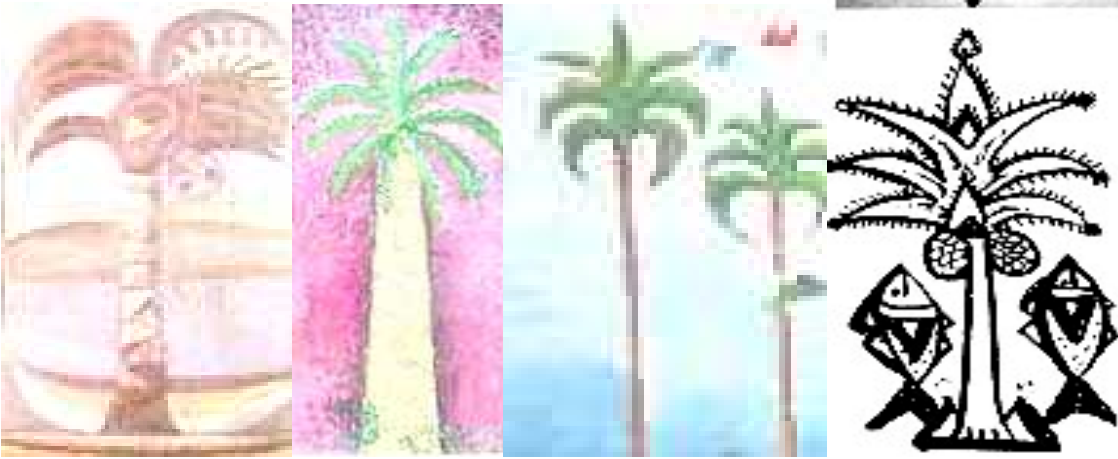

شكل (A)

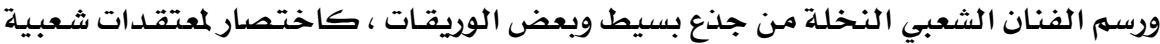

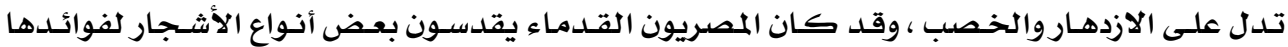

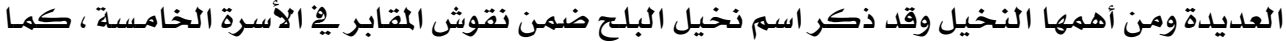

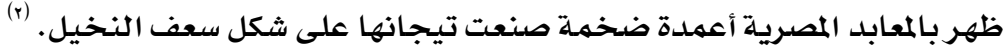

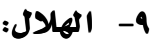

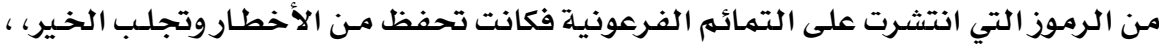

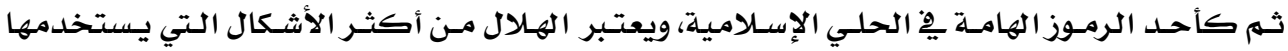

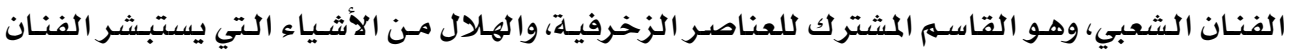

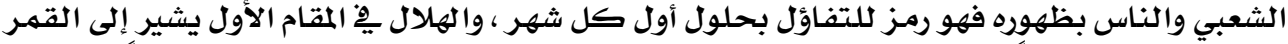

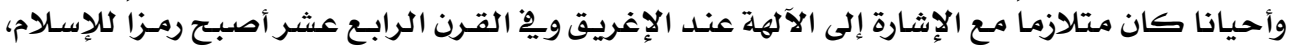

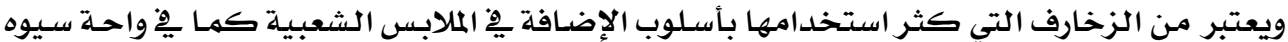

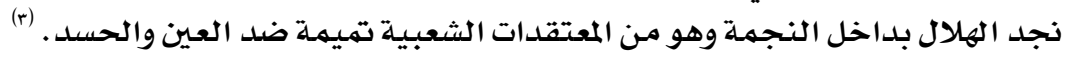

فوزي العنتيل (191VV) بين الفولكلوروالثقافة الشعبية ، الهيئة المصرية العامة للكتاب ، القاهرة. إيمان محمود حسني (1999) ) خواص النخيل يِّالتراث العربي بين الحرف والدلالات الرمزيـة ، مجلـة المأثورات الشعبية ، العدد (ع §) ، القاهرة.

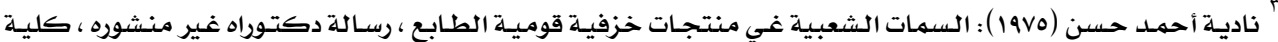
الفنون التطبيقية ، جامعة حلوان. 
1.

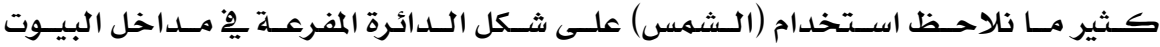

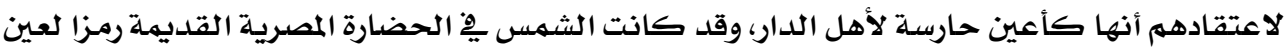

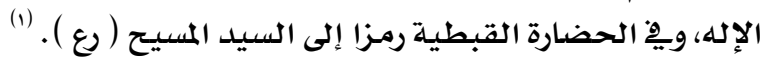

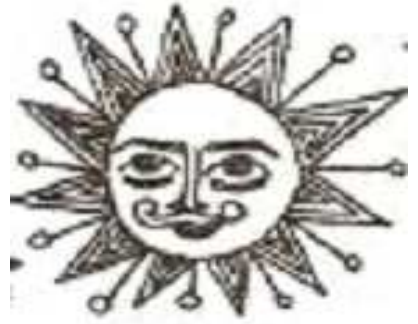

(4) شكل

- 11

يرى المصريون القدماء يِ النجوم أرواح الموتى الذين يـبـحون (رع) ملكهمه وإلههمه، والنجـوم

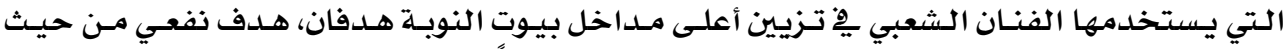

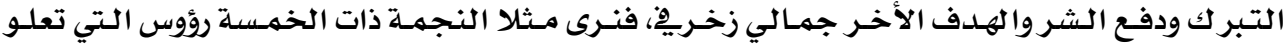
واجهات المداخل يِّأعداد تدور حول قرص الشمس المسنن الذي يتوسط الواجهة كقوة جذب مسـاعدة لمجموعة المثلثات التي أسفلها لشد عـين الغربـاء ، وإبطـال فعـل عيـونهم والنسجوم أيضا رمـز مـن الرمـوز

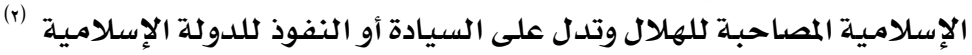
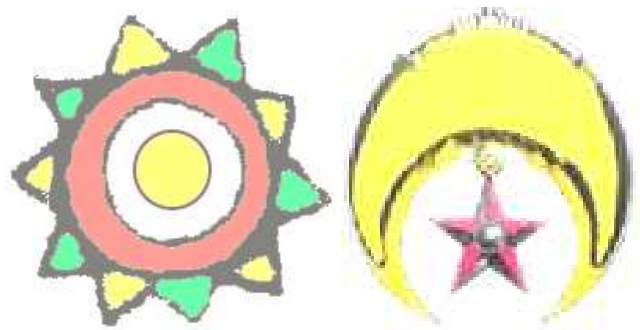

شكل (1.)

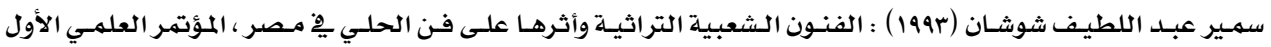
للفنون الشعبية والتراث ، كلية الفنون الجميلة ، جامعة الإسكندرية.

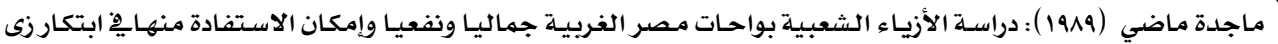
وطني معاصر ، رسالة دكتوراه غير منشورة ، كلية الاقتصاد المنزلي ، جامعة حلوان. 
العـرائس فِ انتراث لتحقيـق هـدفاً وظيفيـا إلى جانــ هيئتهـا الجمـاليـة ، مهـا جعلـها

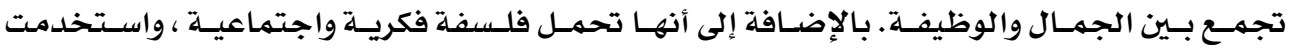

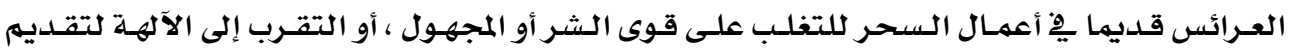

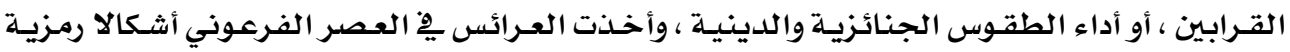

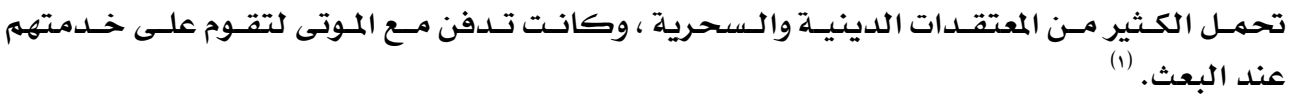
وفِ العصر الإسـلامس ظهرت أنواع مختلفة من العرائس مثل عروسة المولد وخيال الظل

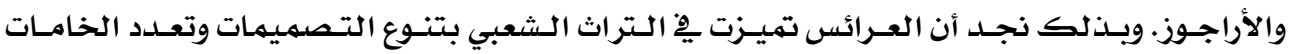

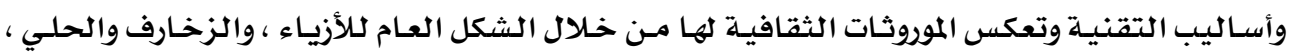

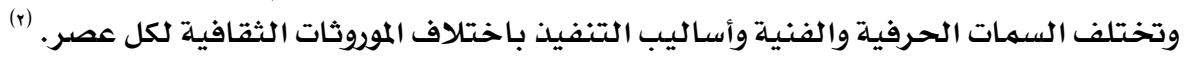

با - عروســــة المولـد

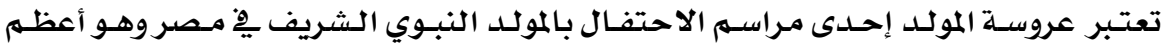

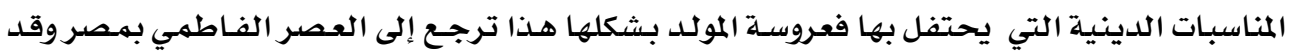

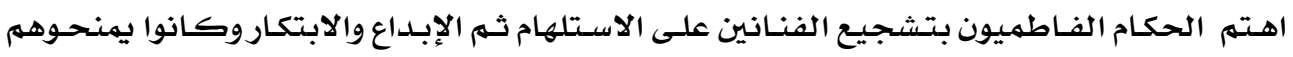
العطايا مها كان له أكبر الأثر على الفنان الشعبي ، فكان من أبدع تلـك التحف نهـاذج مـن الحلـوى

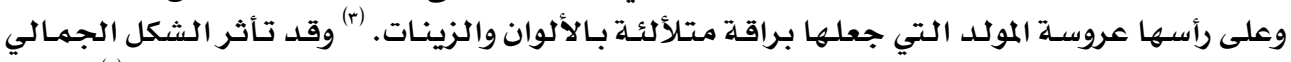

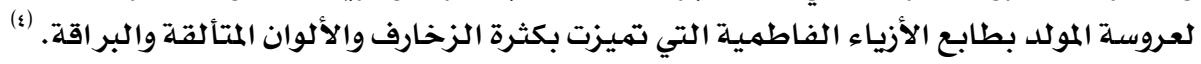
18- مرائـس القمـاث: هي عرائس تصنـع من القماث وتحشى بـالقطن ليلعب بها الأطفال ولتفي بـبعض الأغـراض

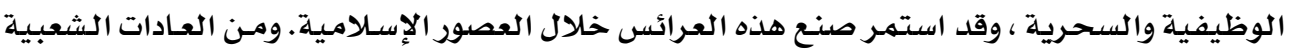

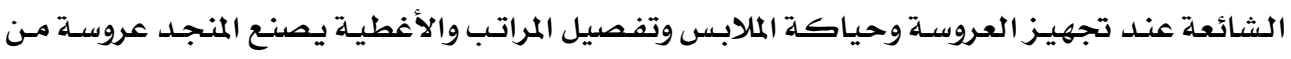

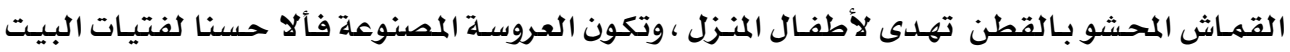

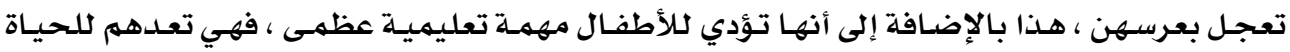

نادية أحمد حسن (19v0) ): مـرجع سـابق

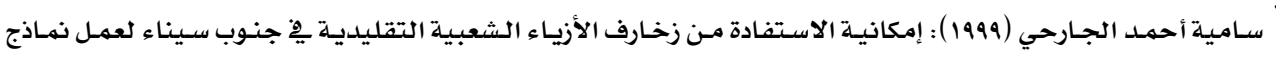

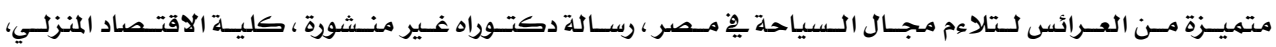
جامعة حلوان. "َ أكرم قانصو (1990) ): التصوير الثعبي العربي ، المجلس الوطني للثقافة والفنون ولآداب بالكويت. " زينب حجازي ( (199) ): عروسة المولد ، موسوعة الفنون الشعبية ، الهيئة العامة للاستعلامات ، القاهرة. 


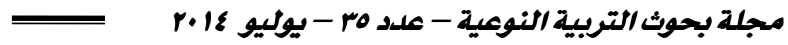

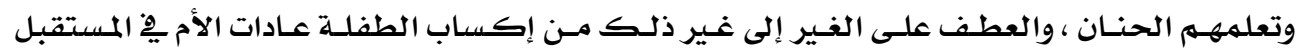

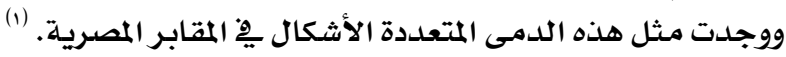

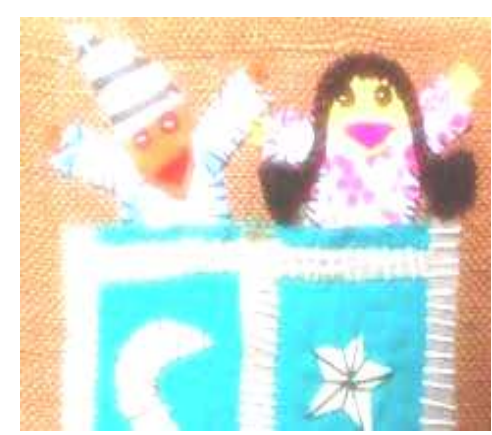

عروسة القماث

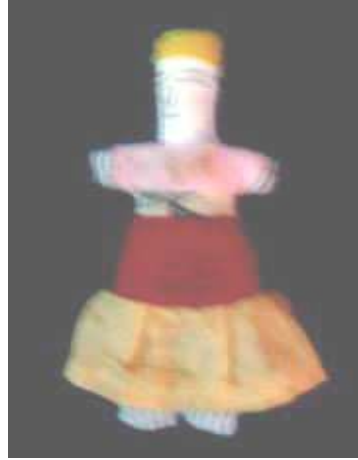

الأراجوز

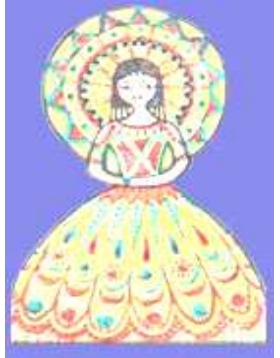

عروسة المولد

(11) شوز

10- الهودج والمحمل

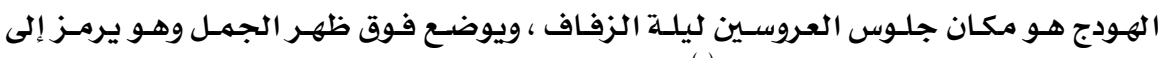

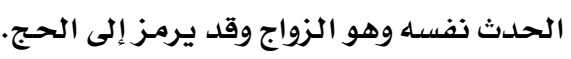

-17 السـيف

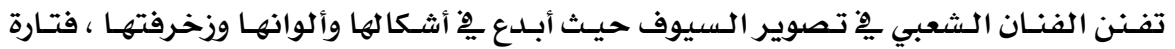

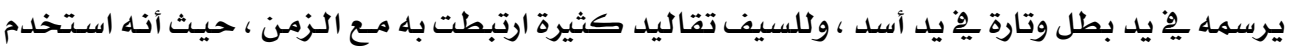

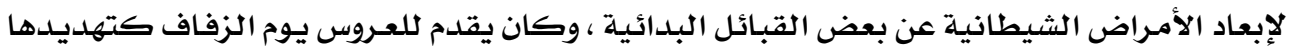

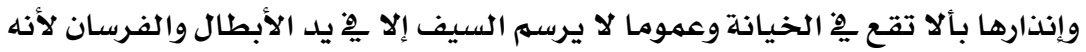

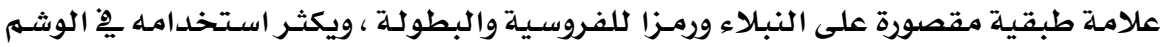

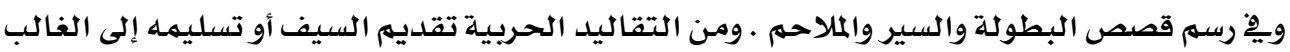

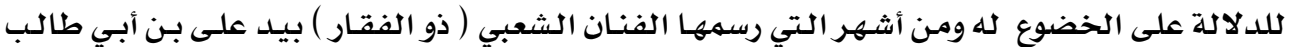

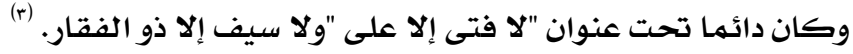

سامية أحمد الجارحي (1999) ): مرجـع سابق

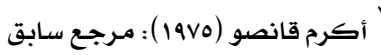

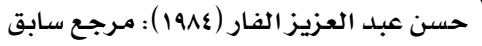



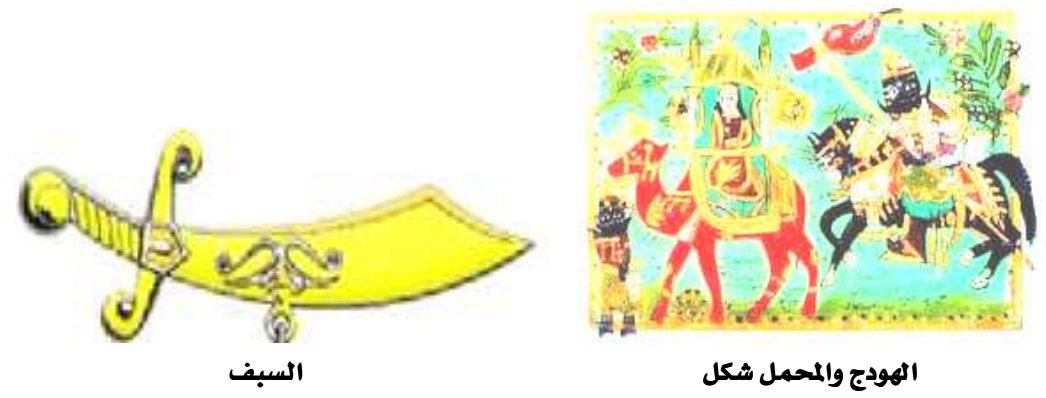

ثكل (ir)

الإبــريـق واتـقـلة

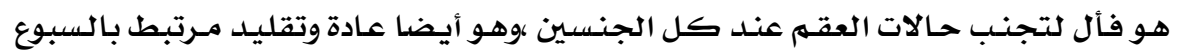
فإذا كان المولود ذكرا أحضر الإبـريق رمـزا للـذكورة ويـزين بـالسبـحـة ، والقلـة وهي رمـز لكلأنوثة وهـي مـرتبطة أيضا بالسبوع . (1)

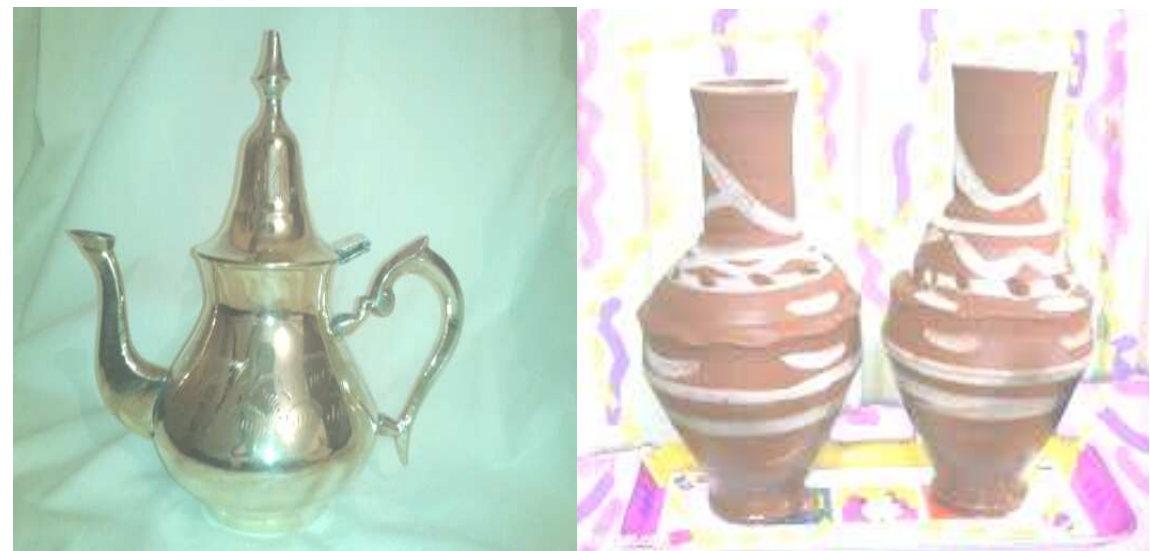

شكل (ir)

$$
\text { -11 }
$$

وهو يرمـز إلى السبوع للهمولود وذلك تبعـا لعادة دق الهون يِّ أذن المولود.

$$
\text { 19- - 19 - مكل الفارس أو المحارب }
$$

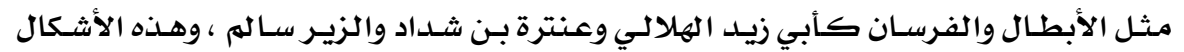
صـورها خيـال الفنـان مـن خـلال القصص والملاحهم الشعبيـة، والـتي يستهدف بهـا إبـراز معـاني الجـرأة أشرف السيد العويلي (1991) ): الفـن الشعبي يِ التصوير المصري المعاصـر ومـداخل استخدامـه ِِّ التربيـة الفنيـة ، رسـالة ماجستير غير منشوره ، كلية التربية الفنية ، جامعة حلوان. 
والشجاعة والمروءة العربية الأصيلة ، ولأن الشارب ضـخم كان علامسة مميزة للرجولـة الناجحسة، فقـد

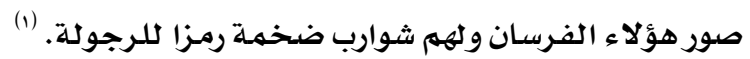

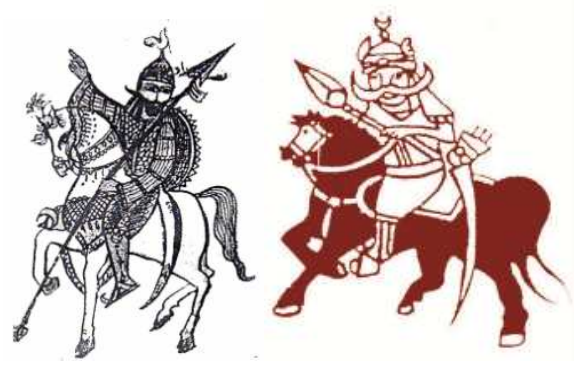

شكل (1\&)

Chaos Theory نظريَّة الفوضى أو (علم اللامتوقع)

مقلدمة:

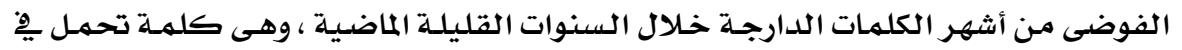

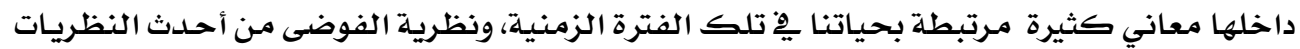

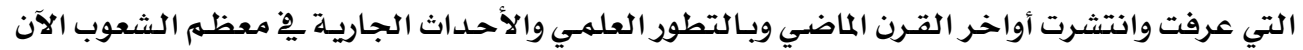

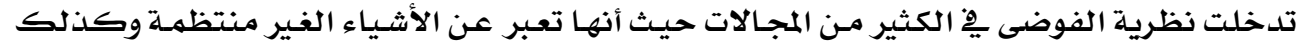

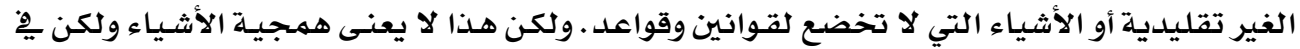

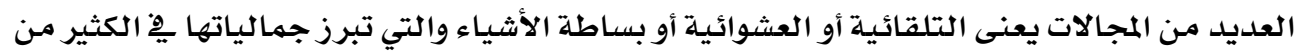

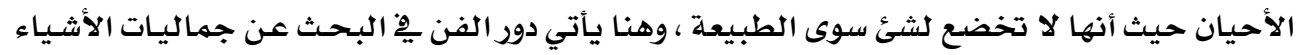

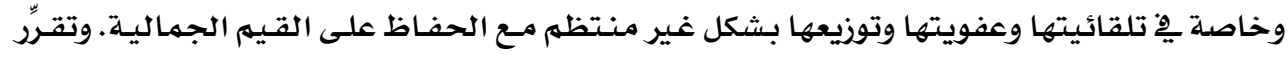

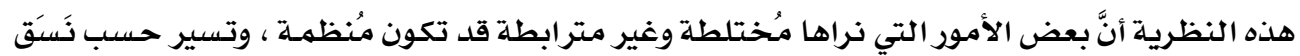

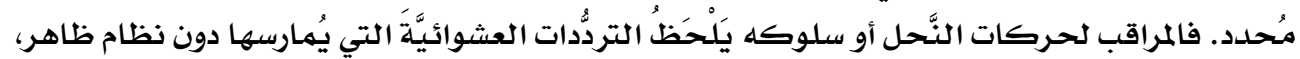

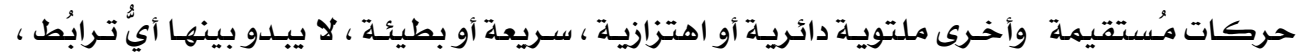

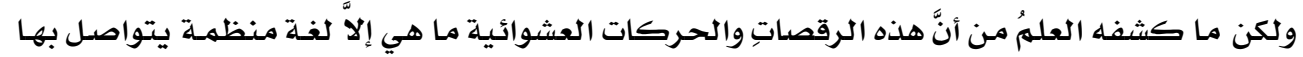

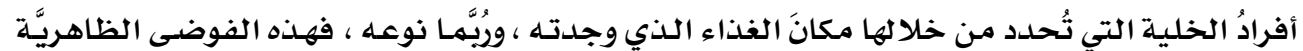

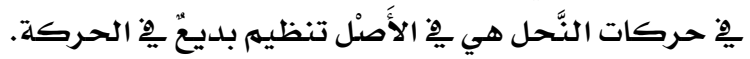

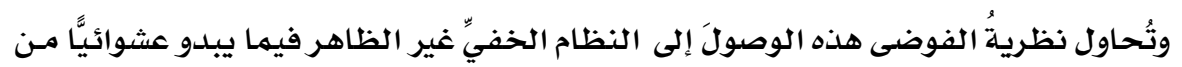

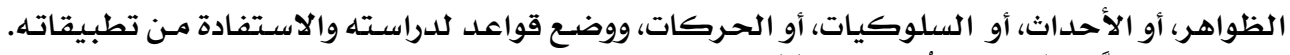

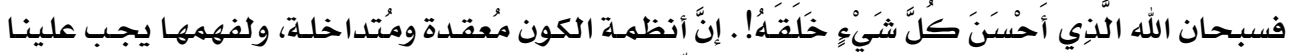

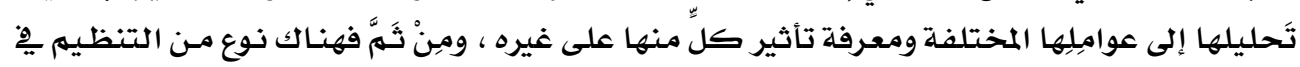

حسن عبد العزيز الفار (عد19 ) : مرجـع سابق 


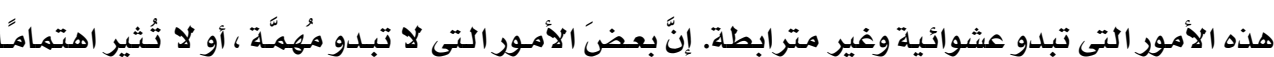

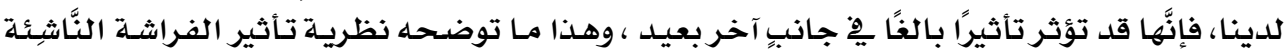

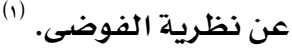
تعريف نظرية الفوضى:

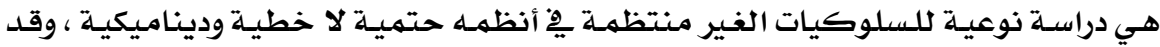
لوحظ السلوك العشوائي عندما لم يكن هناك تغير . ووصفت حالة النظام التي تتكيف مـع تكرار القيهم

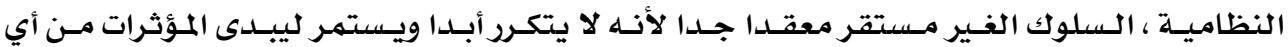
اضطراب صغير.

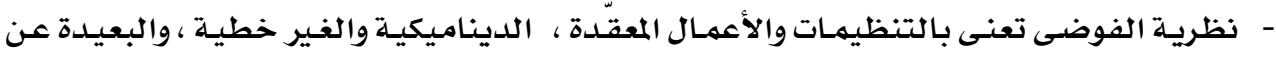

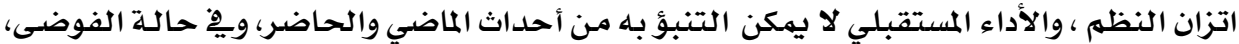

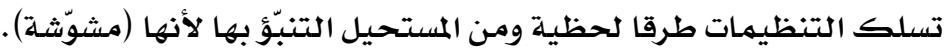

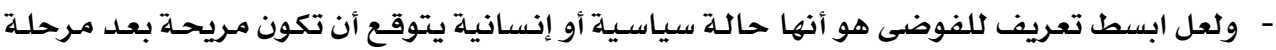

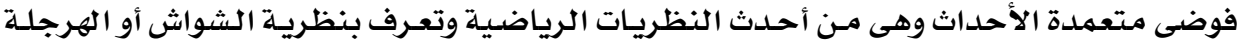

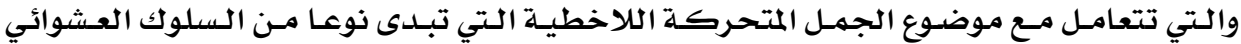

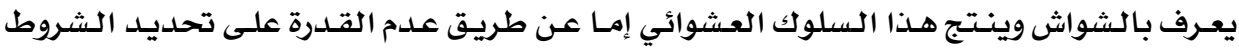

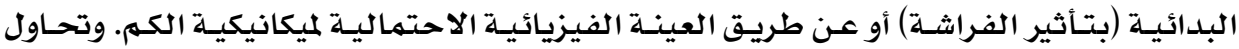

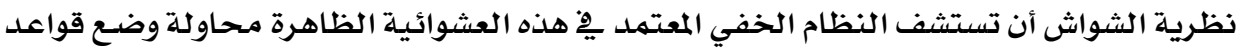

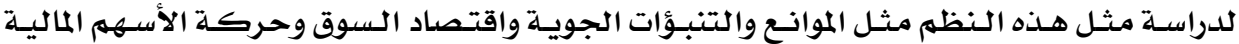

$$
\text { والتزايد السكاني. (r) }
$$

\section{ويمكن أن نلخص نظرية الفوضى فِ النقاط التالية:}

ا- أن النظم الفوضوية نظم لها درجه عاليه من التعقيد (complexity) والتعقيد هنا يعني انه لا

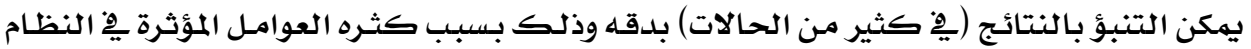

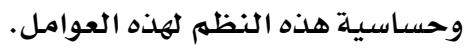

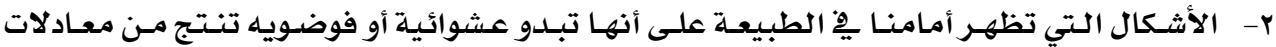

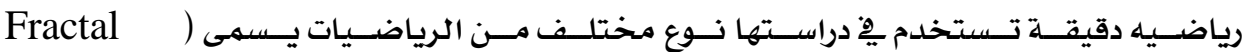

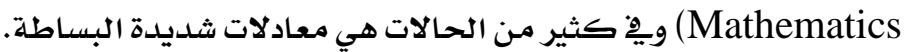
r- يمكن أن ينتج نظام معقد جدا من مدخلات بسيطة.

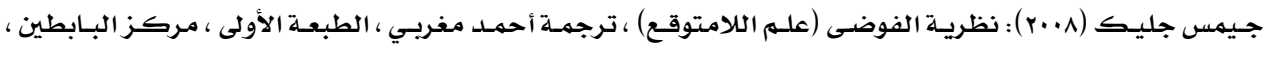
بيروت ، لبنان.

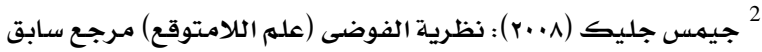
${ }^{3}$ Fractals and Chaos, An Illustrated Course Paul S Addison, Napier University, Edinburgh. 


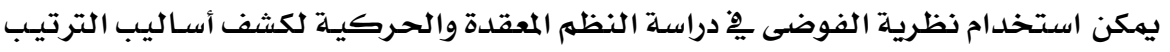

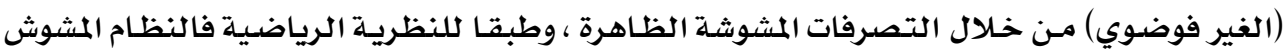

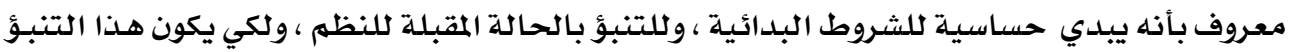

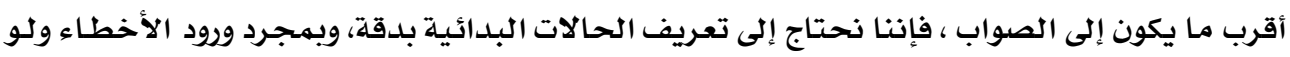

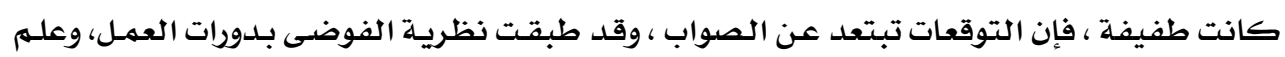

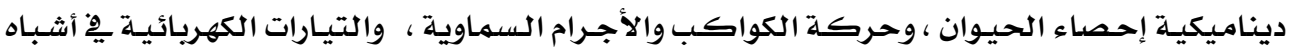

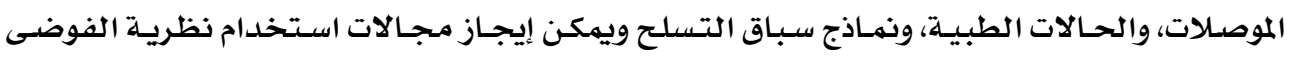
مِّ الآتي:

$$
\begin{aligned}
& \text { 1- العلوم الاجتماعية }
\end{aligned}
$$

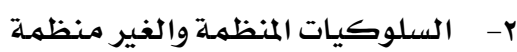

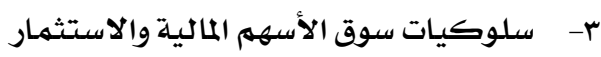

$$
\begin{aligned}
& \text { ع- التنبؤ بحالة الطقس } \\
& \text { 0- نماذج نظم التصنيع } \\
& \text { צ- خلق مقاطع وهى صور منتجة بواسطة الحاسب الآلي. }
\end{aligned}
$$

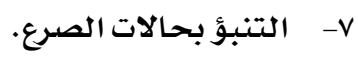

$$
\begin{aligned}
& \text { ^- - م- اتخاذ القرارات المعقدّة }
\end{aligned}
$$

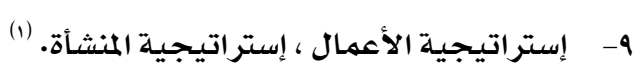

المشفولة الفنية والنسيجية

تعريف المشغولة الفنية:

تعددت مفاهيم المثغولة الفنية ومن أهم هذه المفاهيه:

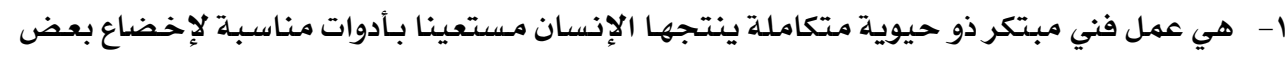

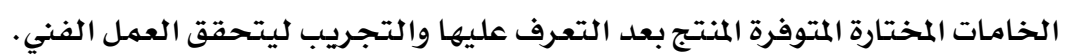

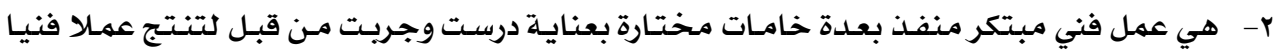

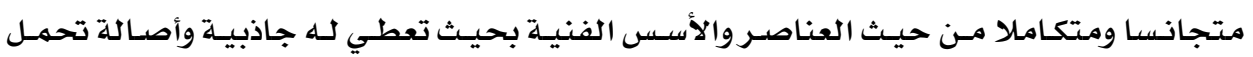

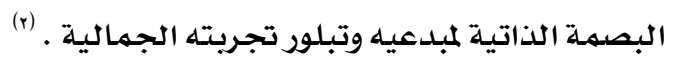

${ }^{1}$ http://yanabeealiraq.com/writers_folder/salam-kabaa_folder.htm

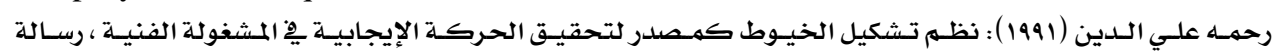

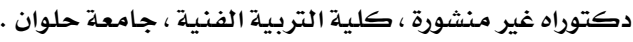


عل الاستفادة من بعض عناصر الفن الشعبي المصري فِ إثراء المشغولة النسيجية باستخلام نظرية الفوضى

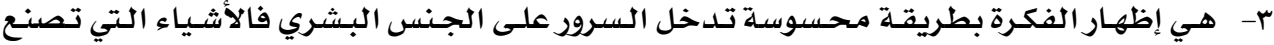

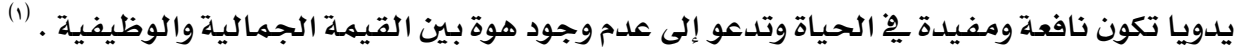

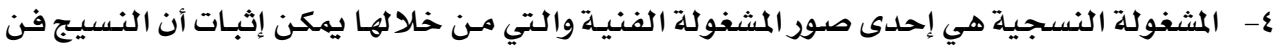

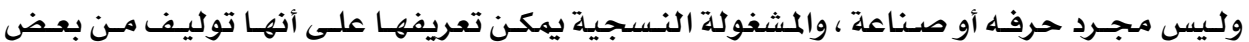

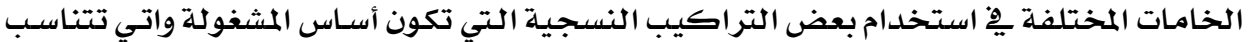
مـع الغرض المصنوعة مـن أجلهـ.

\section{القيم الفنية والجمالية للمشغولات النسجية:}

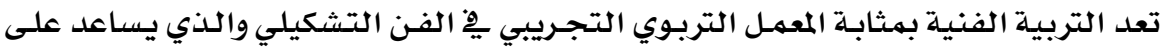

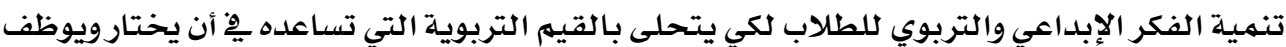

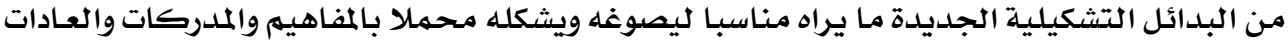

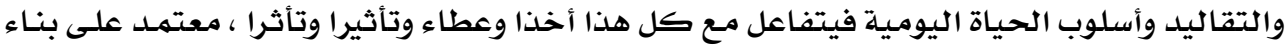

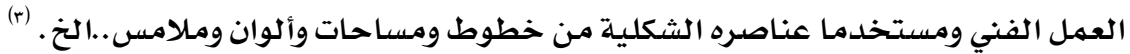
تعريف المعلق النسجي: يمكـن تعريفهـا على أنهـا تلـك المنسـوجـات ذات القيمــة الفنيـة العـاليـة ، والـتي تقـوم بـلدور

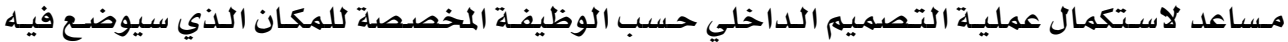

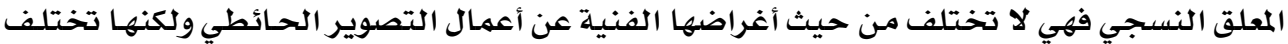

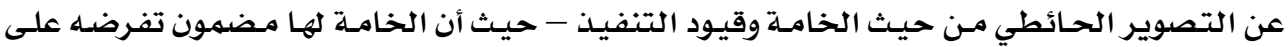

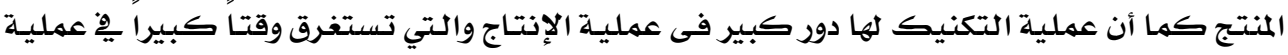

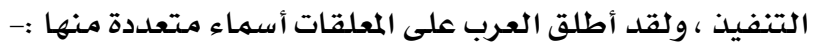
هالقباطي: كان المصريون يطلقون يِّ العصر القبطي على كل مـا يصل إلى أيديهم مـن أنسجة

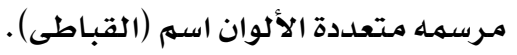
• كما أطلق الإيطاليون اسم أرازى (Arazzi) على المنسوجات المرسمة . • ويطلق عليه اسم الجوبلان نسبة إلى مصنع Gozef Goblin بباريس. • وأيضاً يطلق عليها التابسترى Tapestry وهو اصطلاح إنجليزي يعنى بالعربية اسه القباطي.

هديل حسن إبراهيم (1991) : مدخل لتدريس الإشغال الفنية بالاستعانة بمكملات التربية المصرية القديمة القائمة على

توليف الخامات رسالة ماجستير منشورة ، كلية التربية الفنية زجامعة حلوان .

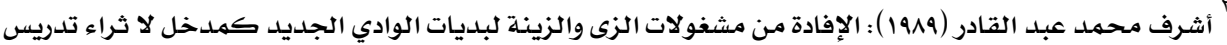
مادة الأثغال الفنية . رسالة ماجستير غير منشورة ـ كلية التربية الفنية . جامعة حلوان.

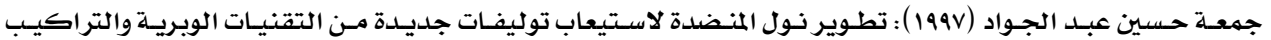
النسيجية الزخرفية ، رسالة دكتوراه غير منشورة ، كلية التربية الفنية ، جامعة حلوان. 
• كما يطلق عليها اسهم الزخرفة المنسوجـة، والنسجيات المرسمة .

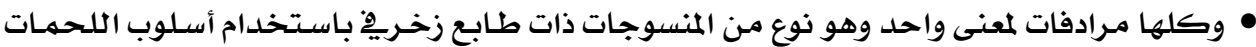

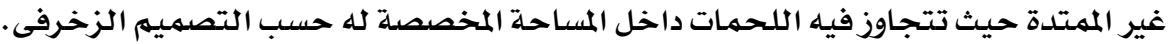
• ويطلق عليها اسم السوماك Soumake weft wraping، وكلمة السوماك مشتقة مـن كلمـة

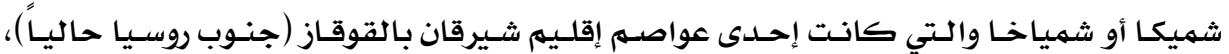

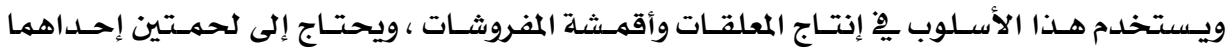

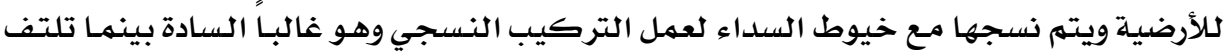

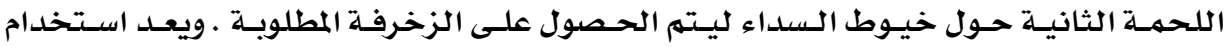

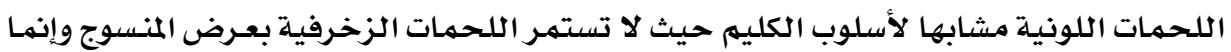

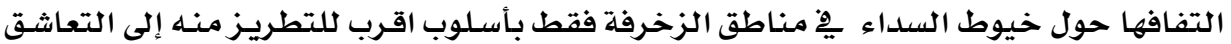

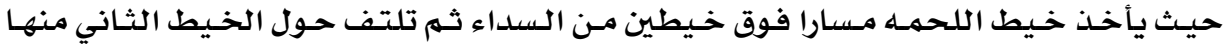

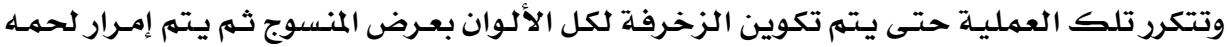

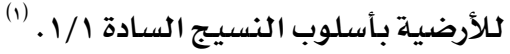
البانب التطبـيـي

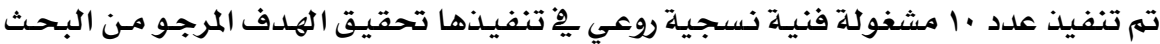

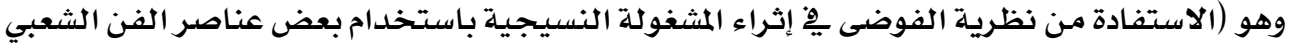

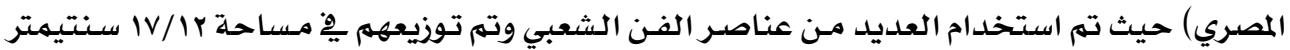

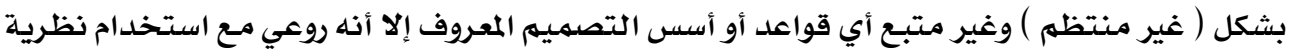

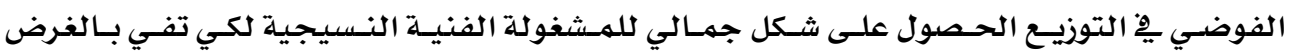

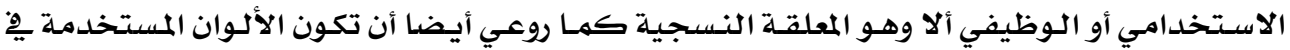

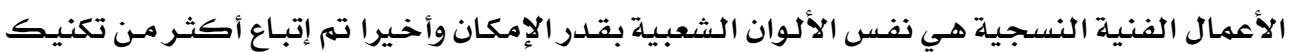

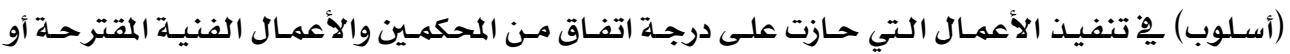

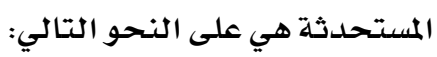

ا. الحمام التي تحمله الأم مصر يخرج من السبت لنشر السلام يِّ أنحاء الدنيا. r. الكف الشعبي بأوضاع وأحجام مختلفة + النخلة المثمرة عدله ومقلوبة يْ شكل غير مألوف. r. القلة القناوي (زير الفقراء) ِِْْ شكل وردة. ع. الكف الشعبي بأحجام مختلفة يبدأ بالأصغر ثم الأكبر فالأكبر على غير المألوف ِِّ المنظور. هـ الهون والقلة القناوي والكف الشعبي وهم جميعا ِِّ أوضاع غير منتظمة (فوضوية). T. . الكف الشعبي يتوسطه العين + الهلال متكرر ويأحجام وأوضاع مختلفة + حدوة الحصان. 


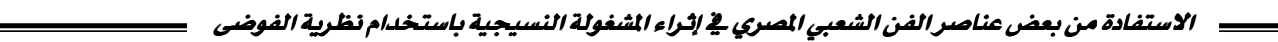
V. الهلال يحتضن عروسة المولد الشمس يِّ أوضاع وأحجام غير منتظمـة ومختلفة. 1. وابور الجازوالقلة القناوي والبر اد الزنك والشمس. 9 ـ الزير والقلة (ثلاجـة الفقراء) والسيف وهـم جميعـا يِّ أوضـاع وأحجـام غير مألوفة مـع الخطوط المتموجهة كرومز للماء. • 1. التنورة مكررة ثلاث مـرات محاطة بالعقرب مـن اليساروأعلى.

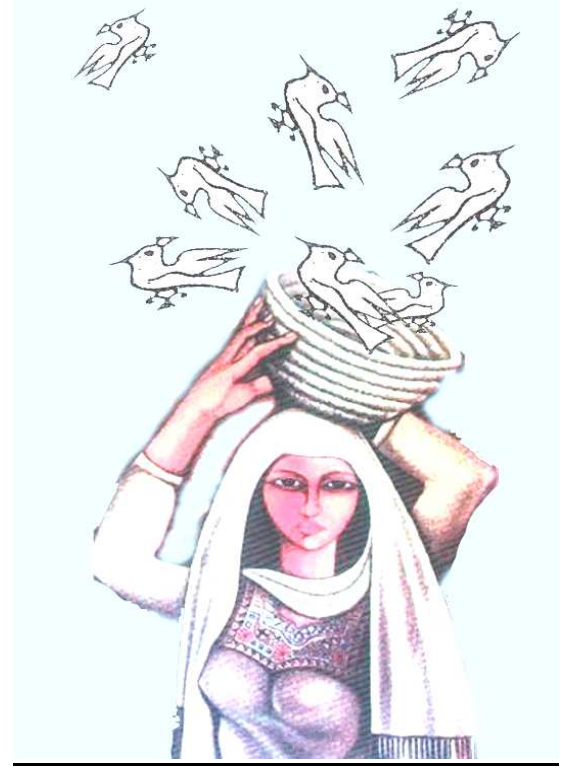

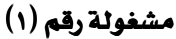

توظيف المشغولة : معلقة نسجية

العنصر الشعبي : الحمام التي تحمله الأم مصر يخرج من السبت لنشر السلام يِ أنحاء الدنيا

الألوان المستخدمة: هي الألوان الشعبية (الأزرق والأبيض والأسود واللبني)

الأسلوب التنفيذي: الخياميه 


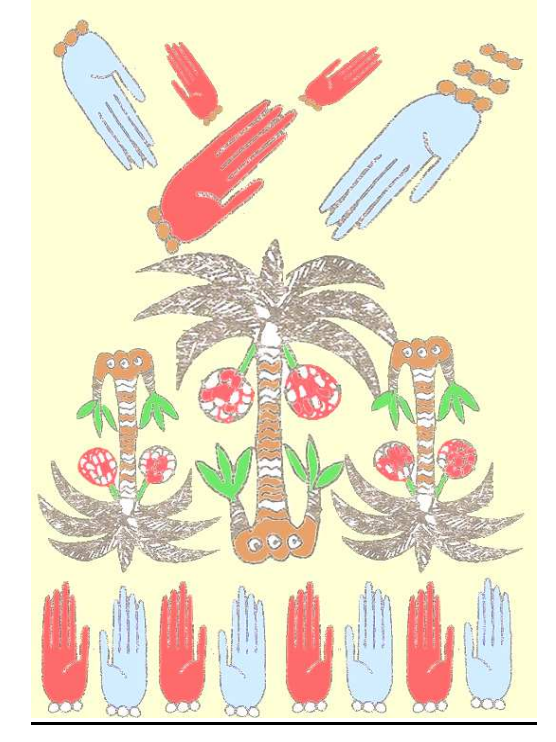

مشغولة رقم (r) توظيف المشغولة : معلقة نسجية

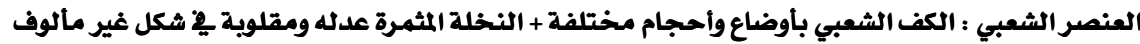

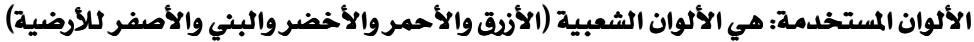

الأسلوب التنفيذي: الوبرة (التافتا)

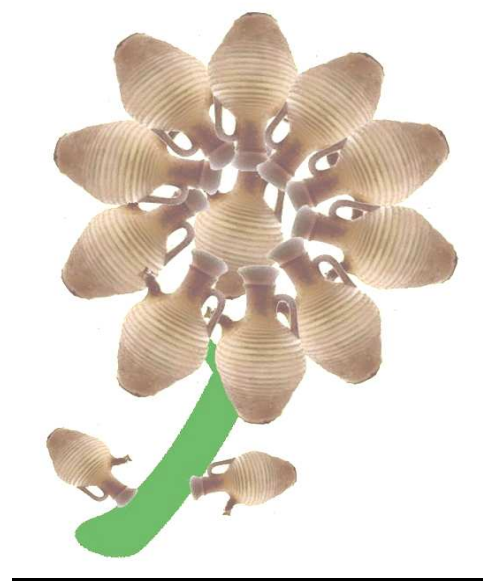

مشغولة رقم (r) توظيف المشغولة : معلقة نسجية

العنصر الشعبي : القلة القناوي (زير الفقراء) مِ2 شكل وردة

الألوان المستخدمة: هي الألوان الشعبية (الأحمر الطوبي والأصفر للأرضية)

الأسلوب التنفيذي: الخيامية 


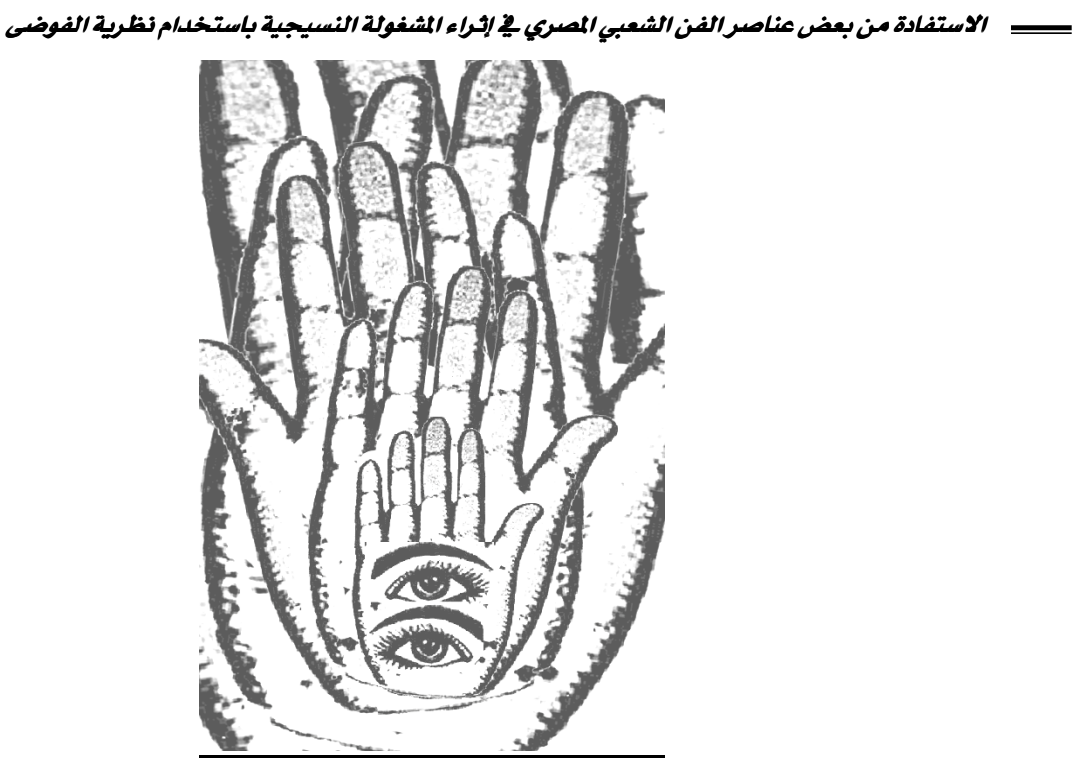

مشفولة رقم (ع) توظيف المشغولة : معلقة نسجية

العنصر الشعبي : الكف الشعبي بأحجام مختلفة يبدأ بالأصفر ثم الأكبر فالأكبر على غير المألوف يف المنظور الطبيعي

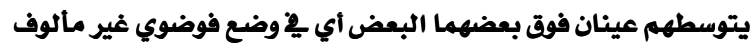

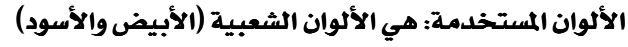

الأسلوب التنفيذي: الوبرة (التافتا)

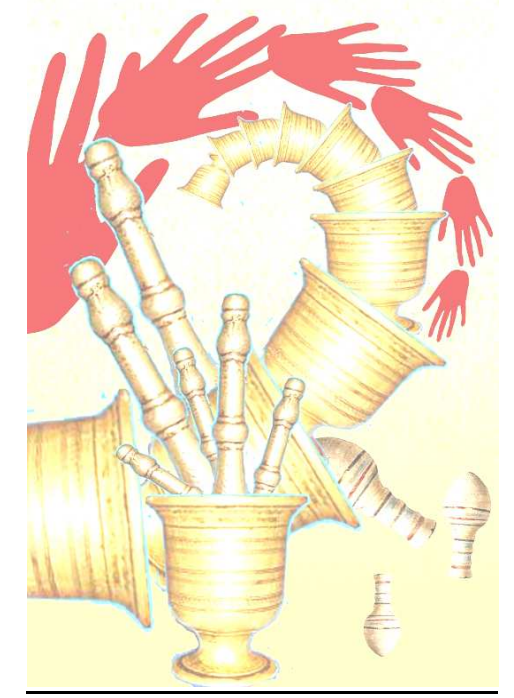

مشغولة رقم (0) توظيف المشغولة : معلقة نسجية

العنصر الشعبي : الهون والقلة القناوي والكف الشعبي وهم جميعا يخ أوضاع غير منتظمة (فوضوية) الألوان المستخدمة: هي الألوان الشعبية (النحاسي للهون والأحمر (لون الدم) للكف والطويسي الفاتح للقله) الأسلوب التنفيذي: النتابستري لإنوانيا 


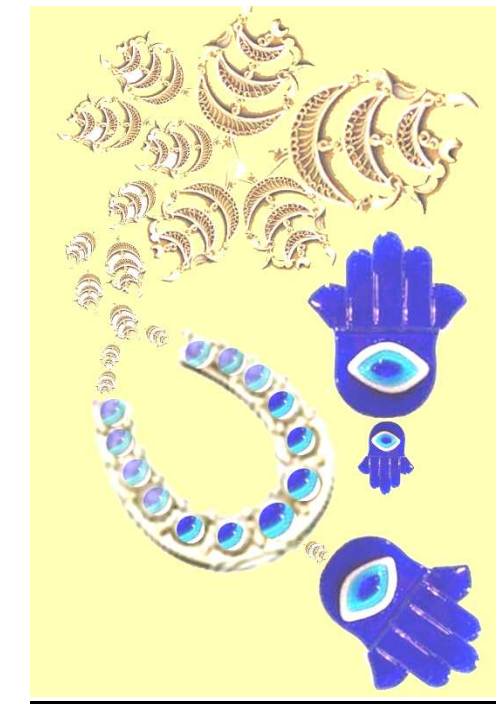

مشغولة رقم (7) توظيف المشغولة : معلقة نسجية

العنصر الشعبي : الكف الشعبي يتوسطه العين + الهلال متكردوباحجام وأوضاع مختلفة + حدوة الحصان

الألوان المستخدمة: هي الألوان الشعبية (الأزرق والأبيض والبني والأصفر لألأرضية) الأسلوب التنفيذي: التابستري

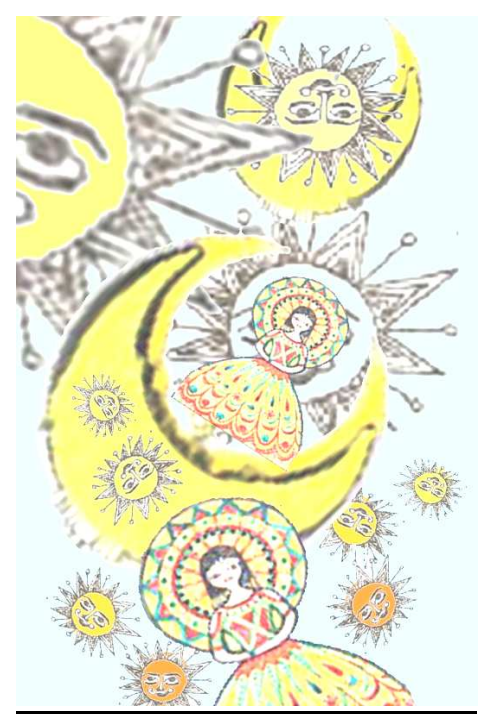

مشغولة رقم (v) توظيف المشفولة : معلقة نسجية

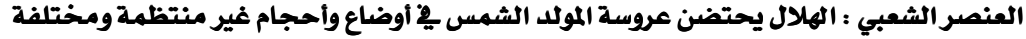

الألوان المستخدمة: هي الألوان الشعبية (الأصفروالأحمروالبني والأسود واللبني للأرضية)

الأسلوب التنفيذي: الخيلة الاهفروالاميرواية 


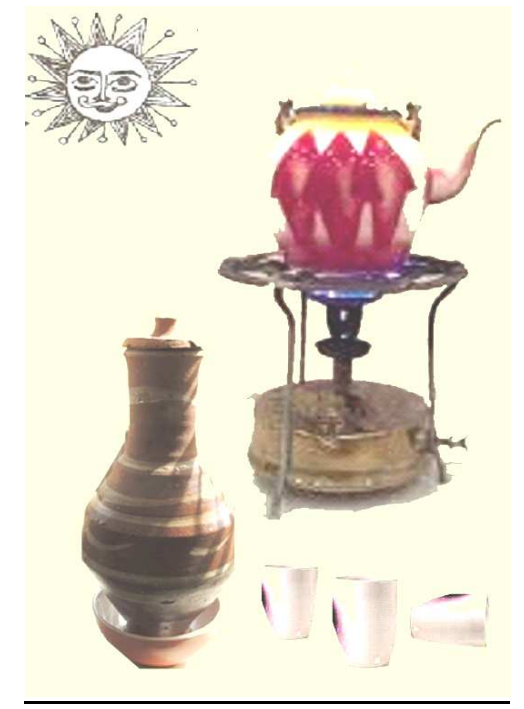

مشغولة رقم (^) توظيف المشغولة : معلقة نسجية

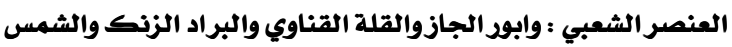

الألوان المستخدمة: (النحاسي للوابوروالأحمر الطوبي للقلة والأبيض والأسود للشمس والأصفر للأرضية) الأسلوب التنفيذي: التابستري

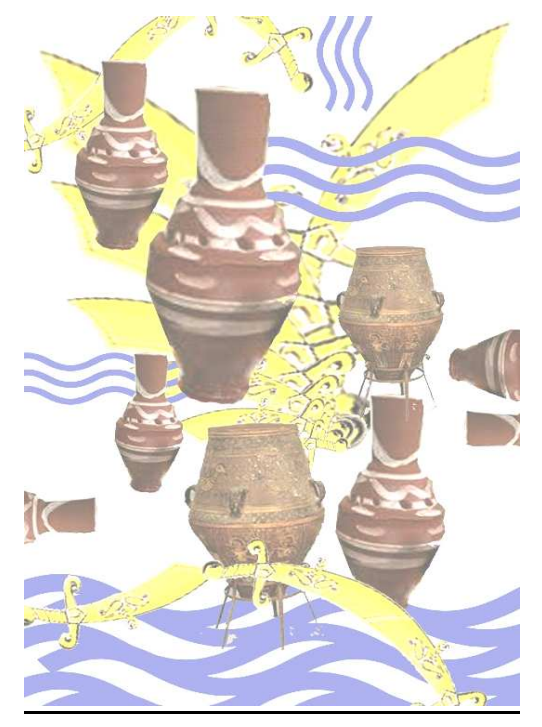

مشغولة رقم (ه) توظيف المشغولة : معلقة نسجية

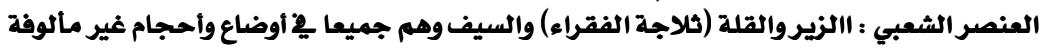

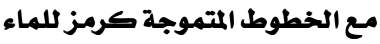

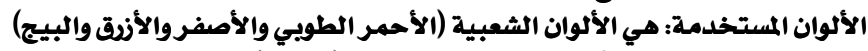

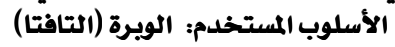




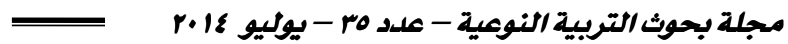

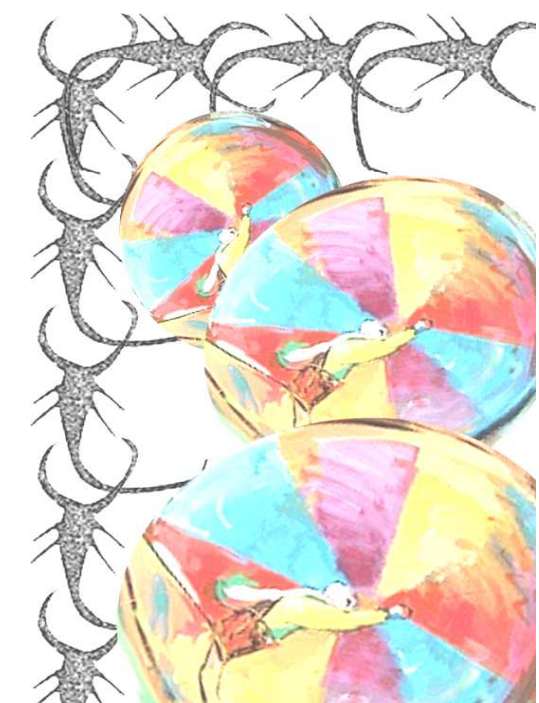

مشغولة رقم (م 1) توظيف المشغولة : معلقة نسجية

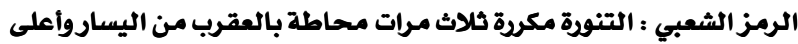

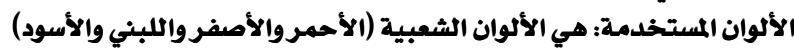
الأسلوب التنفيذي: التابستري (الاحمروالأوفير

النتائج الإحصائية للمشغولات النسجية بطاقة تقييم الشفولات:

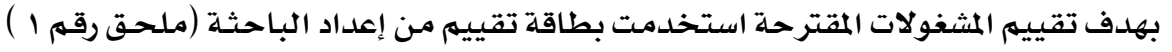

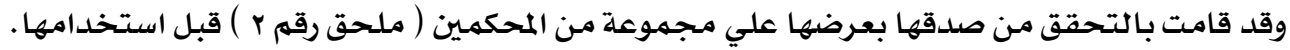

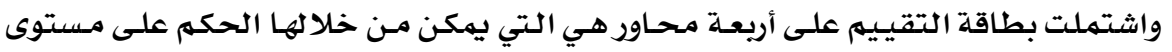

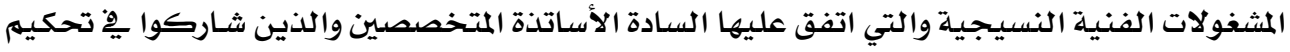
تلك البطاقة، وهذه المحاور هي:

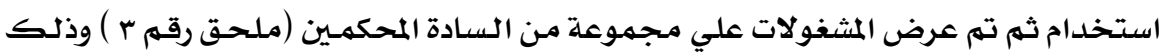
لتقييمها وفقا لبنود استمارة التقييه.

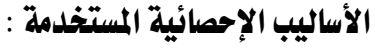
تم استخدام معامل الاتفاق لكنـدال W لتحكيه المشغولات التي صـممتها الباحثة؛ حيث تم

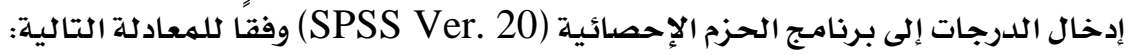
$\mathrm{S}^{2}$

$\mathrm{W}=$

$1 / 12 \mathrm{k}^{2}\left(\mathrm{n}^{3}-\mathrm{n}\right)-\mathrm{k} \sum \mathrm{t}_{\mathrm{k}}$ 
اـ الشفولة النسجية اليدوية رقم (1) والمكونة من المرأة كرمز لمصر تحمل سبت يطير منه حمام أبيض لنشر السلام في أنحاء اللدنيا.

يوضح الجدول التالي رقم ( 1 ) نتائج تحكيم هذه المثغولة.

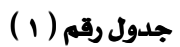

\begin{tabular}{|c|c|c|c|c|c|c|}
\hline الدلالة & SIS & قيمة W & درجات الحرية & متوسط الرتب & المتوسط & تقيييم المحاورارجة \\
\hline \multirow{4}{*}{0.001} & \multirow{4}{*}{41.293} & \multirow{4}{*}{0.860} & \multirow{4}{*}{4} & 2.58 & 22.08 & توافر عنصر الفن الشعبي \\
\hline & & & & 3.38 & 23.25 & استخدام نظرية الفوضى \\
\hline & & & & 1.00 & 13.50 & مناسبة الأسلوب المستخلم \\
\hline & & & & 2.04 & 22.42 & توظيف المشفولة \\
\hline
\end{tabular}

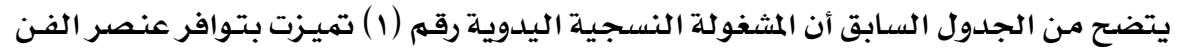

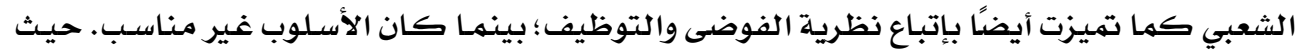

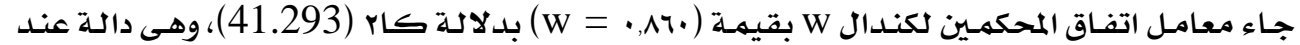

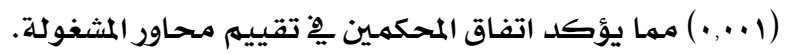
rـ المشفولة النسجية رقم (r) والمكونة من رمز الكف والنخلة بأوضاع وأحجام مختلفة. يوضسح الجدول التالي رقم ( r ) نتائج تحكيم هذه المثغولة.

جدول رقم (r )

\begin{tabular}{|c|c|c|c|c|c|c|}
\hline 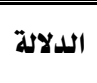 & rL & قيمة W & درجات الحرية & متوسط الرتب & المتوسط & تقييي المحاور اللدرجة \\
\hline \multirow{4}{*}{0.001} & \multirow{4}{*}{41.043} & \multirow{4}{*}{0.855} & \multirow{4}{*}{4} & 2.67 & 21.75 & توافر عنصر الفن الشعبي \\
\hline & & & & 3.46 & 23.00 & استخدام نظرية الفوضى \\
\hline & & & & 1.00 & 15.17 & مناسبة الأسلوب المستخلدم \\
\hline & & & & 2.88 & 22.33 & توظيف المشفولة \\
\hline
\end{tabular}

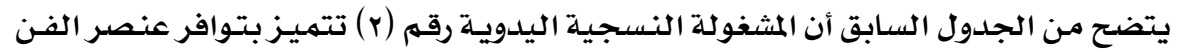

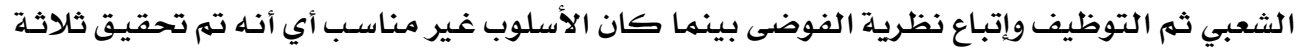

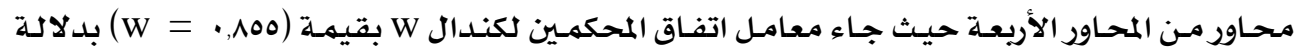

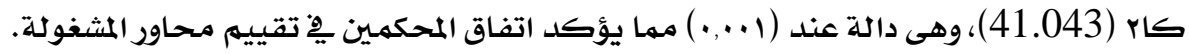




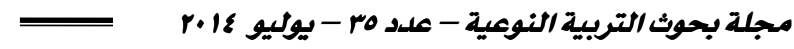

بـ الششفولة النسجية رقم (广) والككونة من القلة القناوي مكررة على شكل وردة.

يوضـح الجدول التالي رقم ( r ) نتائج تحكيم هذه المشغولة.

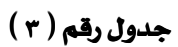

\begin{tabular}{|c|c|c|c|c|c|c|}
\hline الدلالة & SI & قيمة W & درجات الحرية & متوسط الرتب & المتوسط & تقيييم المحاورل الدرجة \\
\hline \multirow{4}{*}{0.001} & \multirow{4}{*}{33.911} & \multirow{4}{*}{0.706} & \multirow{4}{*}{4} & 3.13 & 23.58 & توافر عنصر الفن الشعبي \\
\hline & & & & 3.13 & 23.33 & استخدام نظرية الفوضى \\
\hline & & & & 2.75 & 21.58 & مناسبة الأسلوب \\
\hline & & & & 1.50 & 18.00 & توظيف المشفولة \\
\hline
\end{tabular}

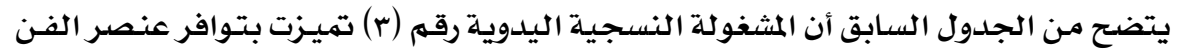

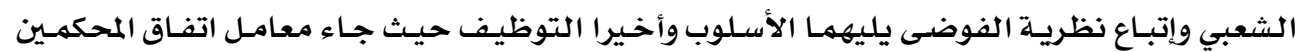

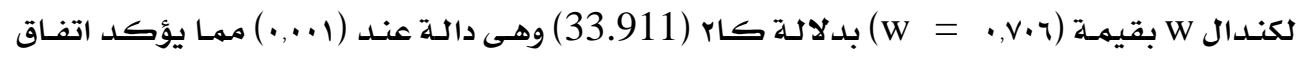

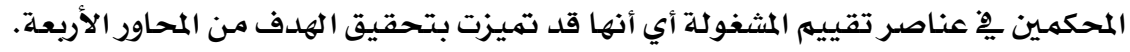
عـ المشفولة النسجية رقم (₹) والمكونة من الكف روالعين مكررين بشكل فوضوي. يوضتح الجدول التالي رقم ( ع ) نتائج تحكيم هذه المثغولة.

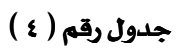

\begin{tabular}{|c|c|c|c|c|c|c|}
\hline الدلالة & SI & قيمة W & ل درجات الحرية & متوسط الرتب & المتوسط & تقيييم المحاور الدرجة \\
\hline \multirow{4}{*}{0.001} & \multirow{4}{*}{28.785} & \multirow{4}{*}{0.600} & \multirow{4}{*}{4} & 2.08 & 20.83 & توافر عنصر الفن الشعبي \\
\hline & & & & 2.92 & 21.42 & استخدام نظرية الفوضى \\
\hline & & & & 2.50 & 21.08 & مناسبة الأسلوب \\
\hline & & & & 2.50 & 21.08 & توظيف المشفولة \\
\hline
\end{tabular}

يتضح من الجدول السـابق أن المشغولة النسجية اليدوية رقم (ع ) قد حققت الأهداف المرجـوة

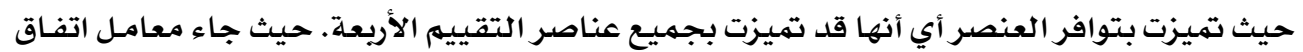

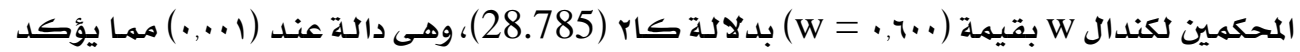

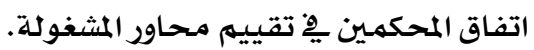
هـ المشفولة النسجية رقم (0) والمكونة من الهوز النحاس والكف والقلة في أوضاع فوضوية. يوضسح الجدول التالي رقم ( ه ) نتائج تحكيم هذه المثغولة. 
جدول رقم (0)

\begin{tabular}{|c|c|c|c|c|c|c|}
\hline الدلالة & SI & قيمة W & درجات الحرية & متوسط الرتب & المتوسط & تقييي المحاور الدرجة \\
\hline \multirow{4}{*}{0.001} & \multirow{4}{*}{34.578} & \multirow{4}{*}{0.720} & \multirow{4}{*}{4} & 2.63 & 21.75 & توافر عنصر الفن الشببي \\
\hline & & & & 2.71 & 21.00 & استخدام نظرية الفوضى \\
\hline & & & & 2.17 & 21.33 & مناسبة الأسلوب \\
\hline & & & & 3.50 & 22.75 & توظيف الشغفولة \\
\hline
\end{tabular}

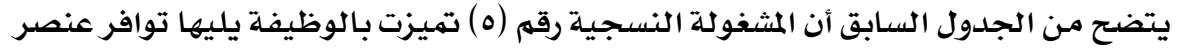

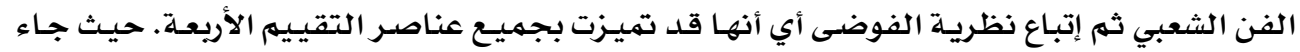

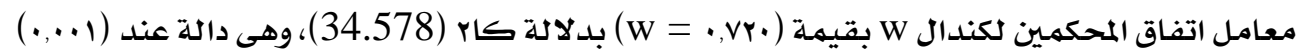

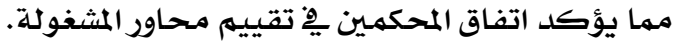

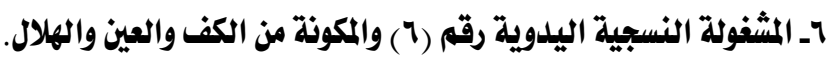
يوضتح الجدول التالي رقم ( T ) نتائج تحكيم هذه المشغولة.

جدول رقم ( ) ج

\begin{tabular}{|c|c|c|c|c|c|c|}
\hline الدلالة & SIS & قيمة W & درجات الحرية & متوسط الرتب & التقوسط & تقييم المحاورل اللدرجة \\
\hline \multirow{4}{*}{0.001} & \multirow{4}{*}{44.608} & \multirow{4}{*}{0.929} & \multirow{4}{*}{4} & 2.96 & 20.75 & توافر عنصر الفن الشببي \\
\hline & & & & 3.96 & 23.17 & استخدام نظرية الفوضى \\
\hline & & & & 1.58 & 18.00 & مناسبة الأسلوب المستخلدم \\
\hline & & & & 1.50 & 17.50 & توظيف المشفولة \\
\hline
\end{tabular}

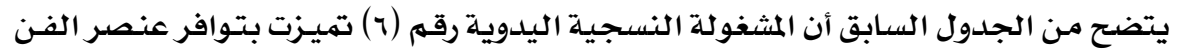

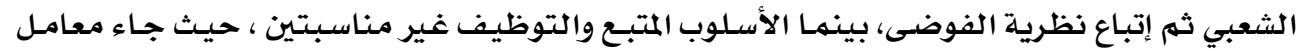

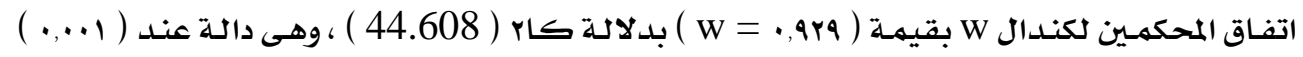

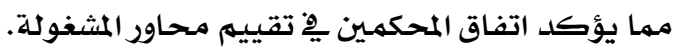

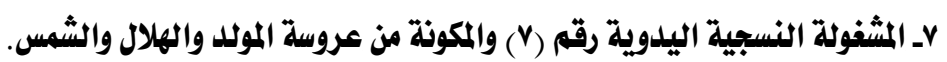
يوضـح الجدول التالي رقم ( v ) نتائج تحكيم هذه المثغولة. 


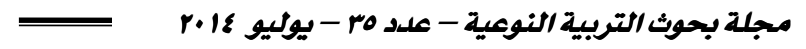

( ) جدول رقم ( )

\begin{tabular}{|c|c|c|c|c|c|c|}
\hline الدلالة & Sו & قيمة W & درجات الحرية & | متوسط الرتب | & المتوسط & تقيييم المحاور الدرجة \\
\hline \multirow{4}{*}{0.001} & \multirow{4}{*}{43.926} & \multirow{4}{*}{0.915} & \multirow{4}{*}{4} & 2.00 & 22.58 & توافر عناصر الفز الشعبي \\
\hline & & & & 2.67 & 23.67 & استخدام نظرية الفوضى \\
\hline & & & & 3.04 & 24.08 & مناسبة الأسلوب المستخلم \\
\hline & & & & 3.29 & 24.25 & توظيف الششفولة \\
\hline
\end{tabular}

يتضح من الجدول السابق أن المشغولة النسجية اليدوية رقم (v) قد تميزت بـالتوظيف يليها

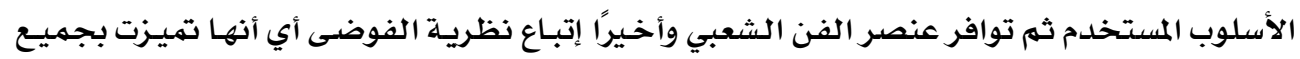

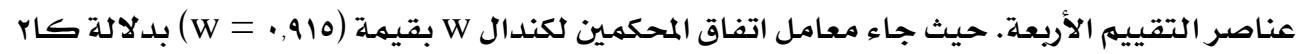

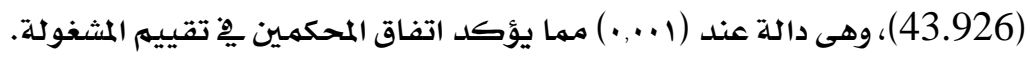

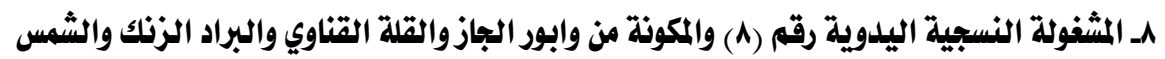

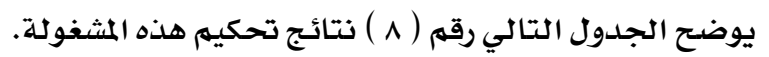

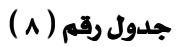

\begin{tabular}{|c|c|c|c|c|c|c|}
\hline الدلالة & SI & قيمة W & درجات الحرية & متوسط الرتب & المتوسط & تقييي المحاور اللدرجة \\
\hline \multirow{4}{*}{0.001} & \multirow{4}{*}{42.212} & \multirow{4}{*}{0.879} & \multirow{4}{*}{4} & 2.00 & 21.08 & توافر عناصر الفن الشعبي \\
\hline & & & & 2.63 & 20.08 & إستخدام نظرية الفوضى \\
\hline & & & & 1.00 & 12.42 & مناسبة الأسلوب المستخلم \\
\hline & & & & 1.38 & 21.50 & توظيف المشفولة \\
\hline
\end{tabular}

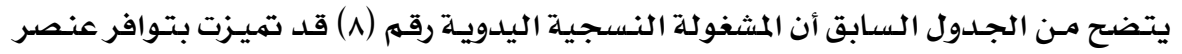

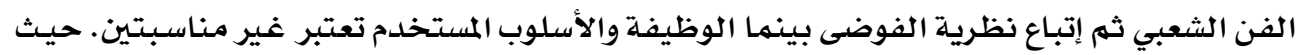

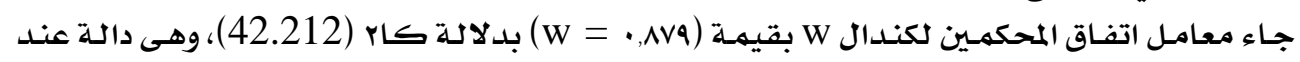

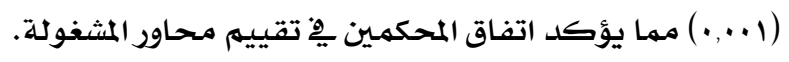

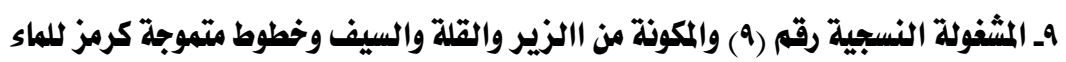
يوضـح الجدول التالي رقم ( 9 ) نتائج تحكيم هذه المثغولة.

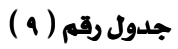

\begin{tabular}{|c|c|c|c|c|c|c|}
\hline الدلالة & SI & قيمة W & درجات الحرية & متوسط الرتب & المتوسط & تقيييم المحاور اللدرجة \\
\hline \multirow{4}{*}{0.001} & \multirow{4}{*}{43.926} & \multirow{4}{*}{0.915} & \multirow{4}{*}{4} & 2.00 & 22.58 & توافر عناصر الفن الشعبي \\
\hline & & & & 2.67 & 23.67 & استخدام نظرية الفوضى \\
\hline & & & & 3.04 & 24.08 & مناسبة الأسلوب المستخلدم \\
\hline & & & & 3.29 & 24.25 & توظيف المشفولة \\
\hline
\end{tabular}


يتضح من الجدول السـابق أن المشغولة النسجية اليدوية رقم (v) قد تميزت بـالتوظيف يليها

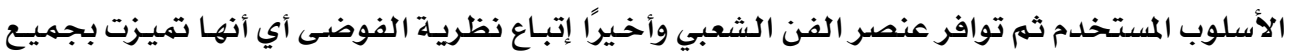

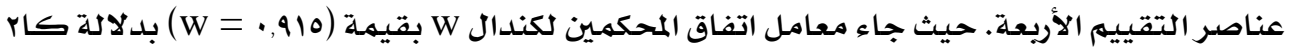

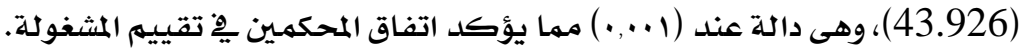

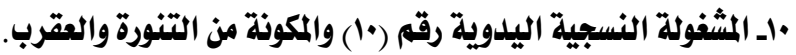
يوضتح الجدول التالي رقم ( • 1 ) نتائج تحكيه هذه المشغولة. جدول رقم ( 1. (1) )

\begin{tabular}{|c|c|c|c|c|c|c|}
\hline الدلالة & Sו & قيهة W & درجات الحرية & متوسط الرتب | & المتوسط & تقيييم المحاور الدرجة \\
\hline \multirow{4}{*}{0.001} & \multirow{4}{*}{43.988} & \multirow{4}{*}{0.955} & \multirow{4}{*}{4} & 2.50 & 22.32 & توافر عناصر الفن الشببي \\
\hline & & & & 2.70 & 23.11 & استخدام نظرية الفوضى \\
\hline & & & & 3.24 & 24.98 & مناسبة الأسلوب المستخلم \\
\hline & & & & 3.11 & 24.16 & توظيف الششفولة \\
\hline
\end{tabular}

يتضح من الجدول السابق أن المشغولة النسجية اليدوية رقم (v) قد تميزت بـالتوظيف يليها

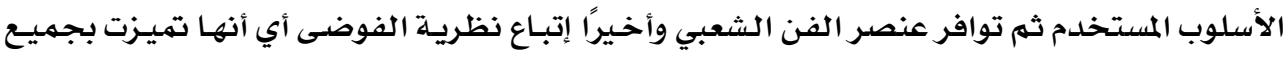

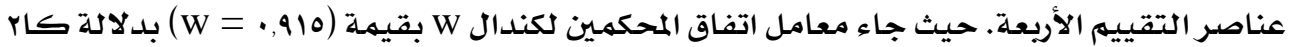

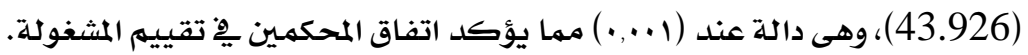

1- ثريا السيد نصر (1991) ): تاريخ أزياء الشعوب ، عالم الكتب ، القاهرة.

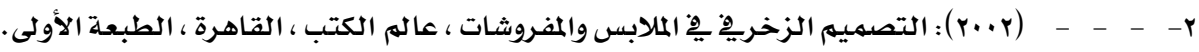

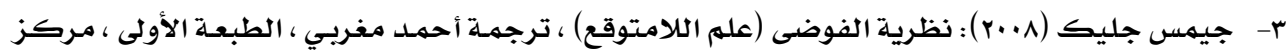
البابطين ، بيروت ، لبنان.

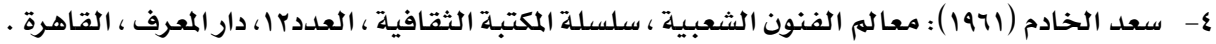

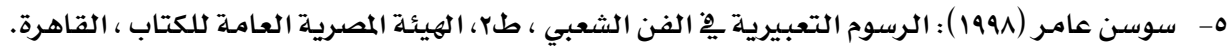

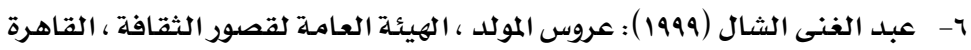

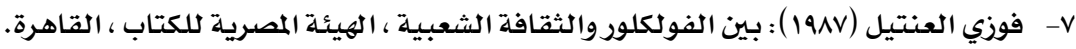

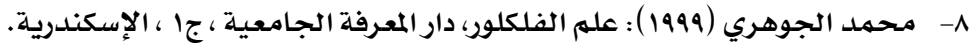

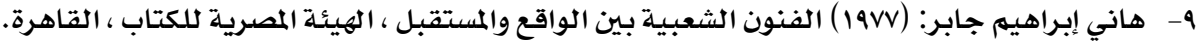

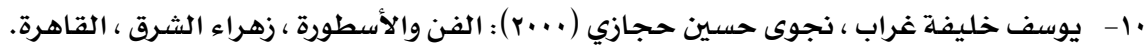




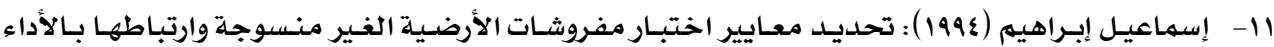

الوظيفي للمنتج النهائي ، رسالة دكتوراه غير منشورة ، كلية الفنون التطبيقية ، جامعة حلوان.

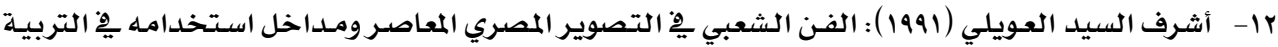
الفنية ، رسالة ماجستير غير منشوره ، كلية التربية الفنية ، جامعة حلوان.

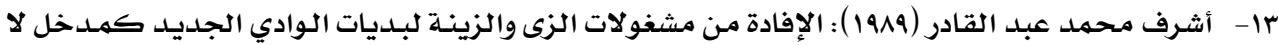

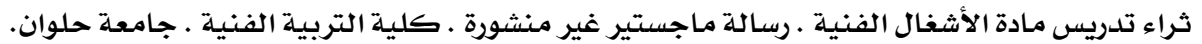
ع ا- جمعة حسين عبد الجـواد (199V)): تطوير نول المنضدة لاستيعاب توليفـات جديدة مـن التقنيـات الوبريـة والتراكيب النسيجية الزخرفية ، رسالة دكتوراه ، كلية التربية الفنية ، جامعة حلوان.

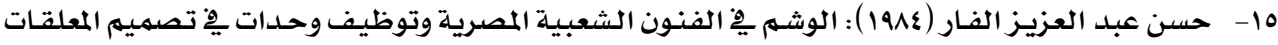
النسجية المطبوعة ، رسالة ماجستير ، كلية الفنون التطبيقية ، جامعة حلوان.

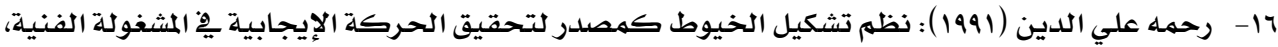

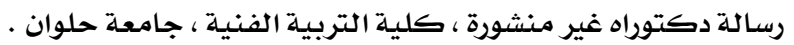

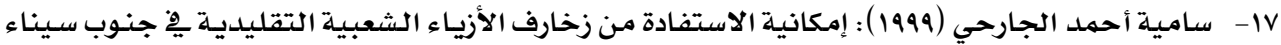

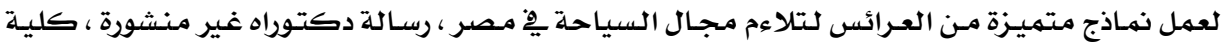
الاقتصاد المنزلي، جامعة حلوان.

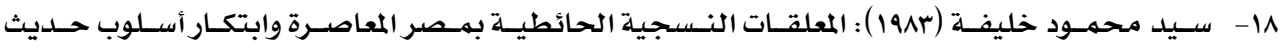

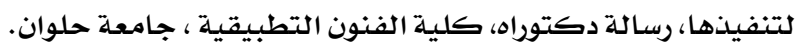

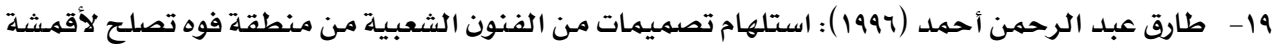

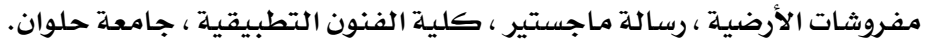

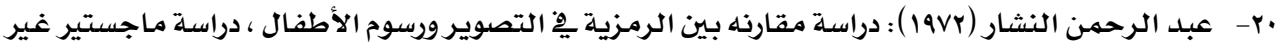

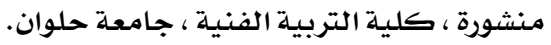

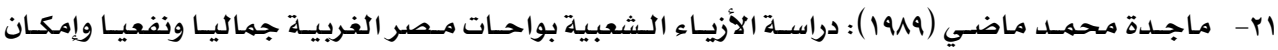

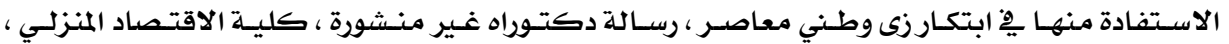

جامعة حلوان.

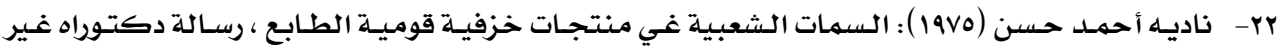
منشوره ، كلية الفنون التطبيقية ، جامعة حلوان.

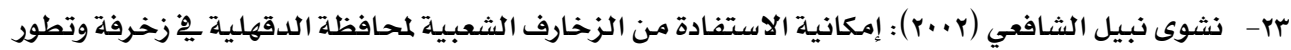
الأزياء المتسمة بالأصالة والمعاصرة للمرأة المصرية ، رسالة ماجستير غير منشورة ، كلية التربية النوعيـة ، جامعة المنصورة.

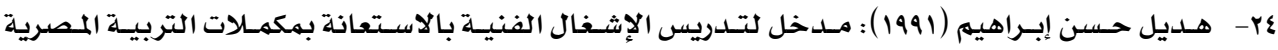

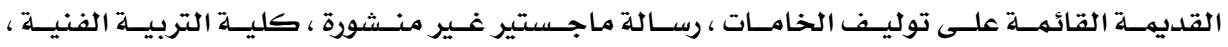
جامعة حلوان . 


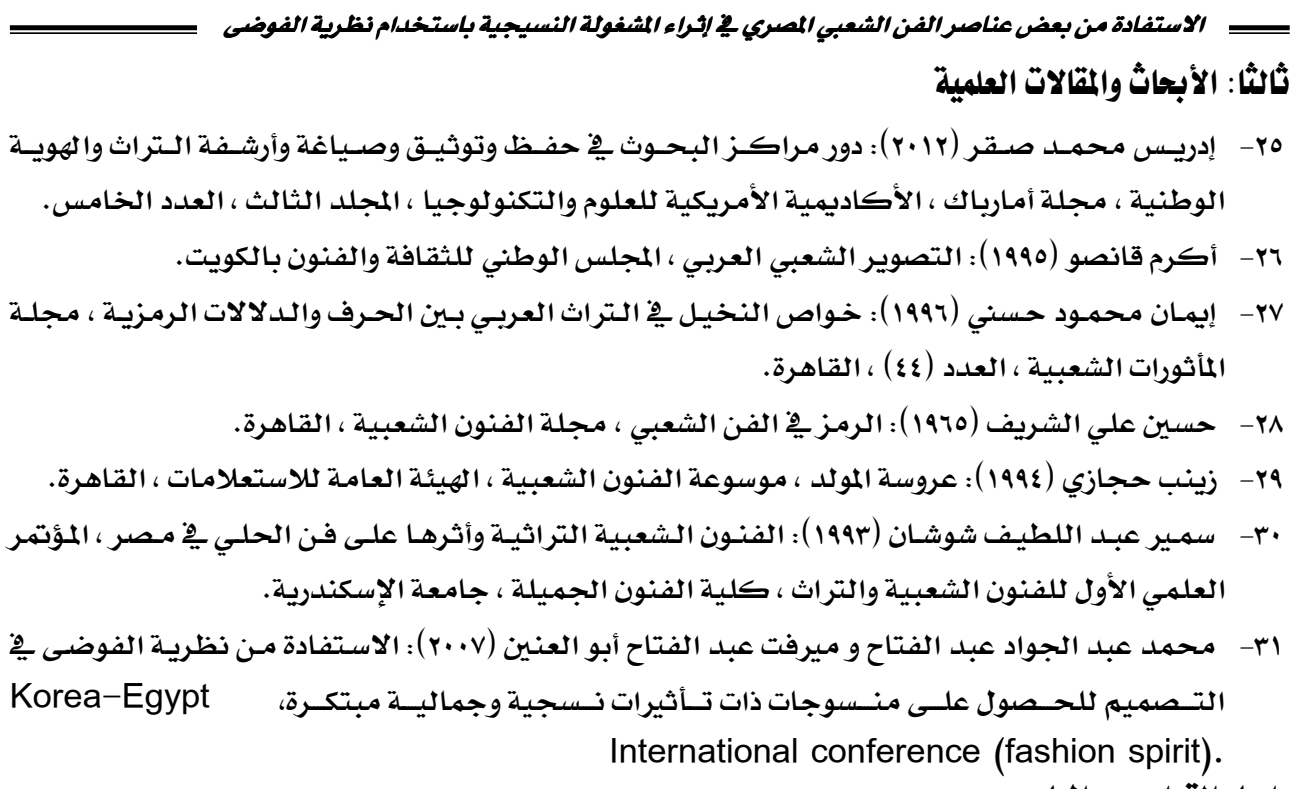

رابعا: القواميس والمعاجم

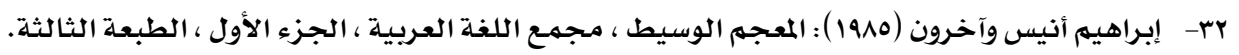

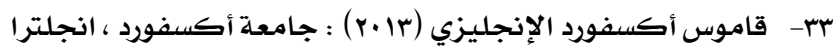
خامسا: المراجع الأجنبية

33-Fractals and Chaos, An Illustrated Course Paul S Addison, Napier University, Edinburgh.

34- http://yanabeealiraq.com/writers_folder/salam-kabaa_folder.htm

سادسا: مواقع الانترنت 


\section{Research Summary}

This study serious attempt to enrich of handmade Weaving by effects of aesthetic innovative rely on some modern scientific theories, a theory of chaos in the design and adopt this theory to explain the formations random appearance, which tend to be irregular, complex and difficult to predict expect as a result, they are subject to the laws and rules of the inevitable, and adopt the main idea for the design of innovative what they contain chaos theory in the design of the basics and configurations with frequent self-similarities and through modern development, which affects the art and can be affected by it in this study, the use of certain symbols of folk art Applying the theory of chaos to enrich the handmade Weaving where it could use some different techniques (such as style or hairy Altavta - Altubbstry - patchwork

Has been handmade Weaving implementing a number 10 technical textile taken into account in its implementation to achieve the desired objective of the research was used, where many elements of folk art have been deployed in (irregular) using the theory of chaos in the distribution for aesthetic form handmade Weaving. 


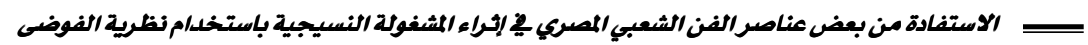

\section{الملاحق}

بسم الله الرحمن الرحيم

السيد الأستاذ الدكتور /

تحية طيبة . وبعد......

تقوم الدارسة / بسمه على السيد زلط المعيدة بقسم التربية الفنية بعمل دراسة استطلاع

رأي استكمالا للحصول على درجة دكتوراه الفلسفة ِِّ التربية الفنية تخصص الأشغال الفنية والشعبية ( نسيج ) بعنوان :

\section{الاستفادة من بعض عناصر الفن الشعبي المصري}

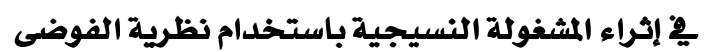

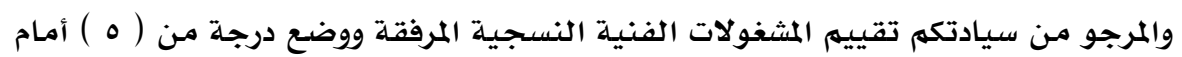

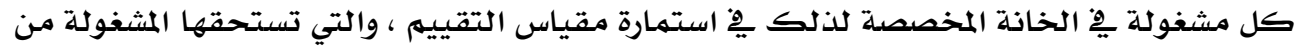

وجهة نظركهم ، ويتكون المقياس من أربعة محاور تشكل معايير التقييم هي:

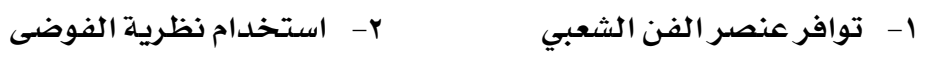

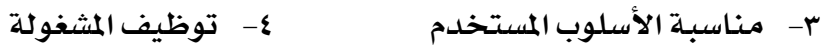

وهذه المحاور افترضتها الباحثة وذلك ِِِ ضوء العوامل والمتغيرات التي اشتقت من خلال

$$
\text { تشغيل هذه المشغولات يِّ المراحل التالية: }
$$

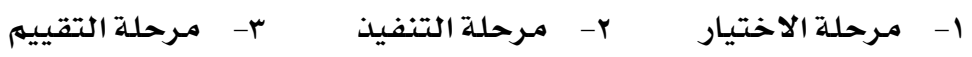

ويمكن إضافة أية أسئلة أو ملاحظات ترونها سيادتكم ضروريية.

ولسيادتكم جزيل الشكر ،،،“،

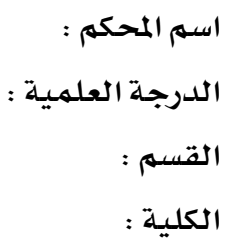




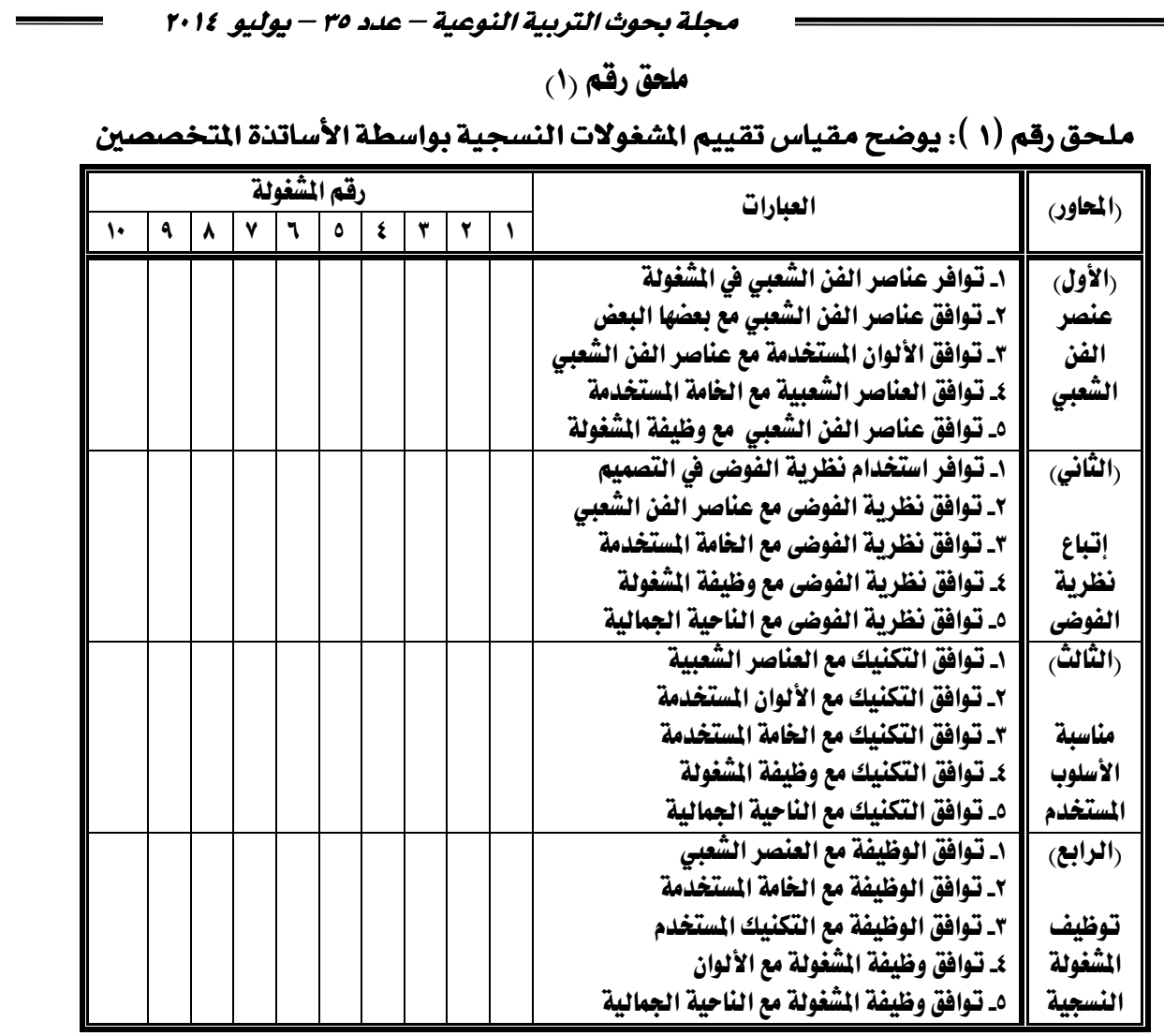

\section{ملحق رقيم (r)}

بيان بأسماء السادة المحكمين لبنود محاور مقياس تقييم المشغولات النسجية

\begin{tabular}{|c|c|c|}
\hline 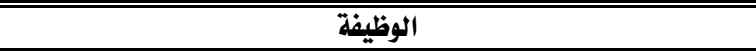 & الاسم & A \\
\hline 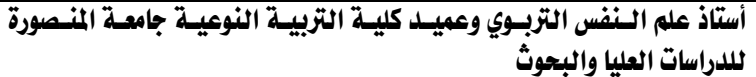 & أ.ـد/ إبراهيه إبراهيه أحمد & 1 \\
\hline أستاذ أصول التربية المتفرغ بكلية التربية النوعية جامعة المنصورة & أ.د / عبد العظيم السعيد مصطفى & $r$ \\
\hline ألمتصاذ النسيج المساعل بقسهم التربيـة الفنيـة بكليـة التربيـة النوعيلة جامعـة & أ.ـ / أشرف عبد الفتاح مصطفي & $r$ \\
\hline 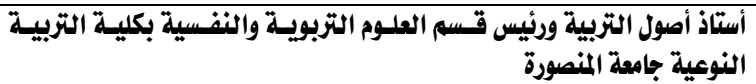 & أ.د/حنان عبد الحلييم رزق & $\xi$ \\
\hline أستاذ علم النفس التزبوي بكلية التربية النوعية جامعة المنصورة & أ.د/ عبد اللّل جاد & 0 \\
\hline أستاذ مساعد متفرغ علم النفس التربوي بكلية التربية النوعية جامعة المنصورة & د/ عبد الرؤف إبراهيم السواح & 7 \\
\hline أستاذ المناهج وطرق التدريس المساعل بكلية التربية النوعية جامعة المنصورة & ده / إحسان الحلبي & $\checkmark$ \\
\hline ملدرس المناهج وطرق التدريس بكلية التربية النوعية جامعة المنصورة & 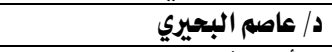 & $\Lambda$ \\
\hline مدرس أصول التربية بكلية التربية النوعية جامعة المنصورة & د/ أحمد فريلد & 9 \\
\hline أستاذ تكنولوجيا التعليم المساعد بكلية التربية جامعة المنصورة & د/ جمال الشرقاوي & $1 \cdot$ \\
\hline
\end{tabular}




$$
\text { ملحق رقم (") }
$$

بيان بأسماء السادة المحكمـين لتقييم المشغولات النسجية المنفذة

\begin{tabular}{|c|c|c|}
\hline 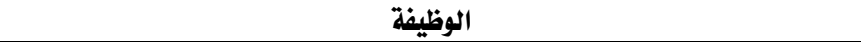 & الاسم - - - الاسم & م \\
\hline أستاذ التراكيب النسجية - كلية الفنوز التطبيقية - جامعة حلوان & أ. أد/ محمد عبد اللّ الجمل & 1 \\
\hline أستاذ مساعد النسيج بقسم التربية الفنية ـ كلية التربية النوعية - جامعة المنصورة & أ.د / أشرف عبد الفتاح مصطفى & r \\
\hline أستاذ تصميم الملابس - كلية الفنوذ التطبيقية - جامعة حلوان & أ.د / محمد البدري عبد الكريم & r \\
\hline أستاذ النسيج - كلية الفنون التطبيقية - جامعة حلوان & أ.د / حسن سليمان رحمة & $\varepsilon$ \\
\hline أستاذ التراكيب النسجية - كلية الفنون التطبيقية - جامعة حلوان & أ. د/ علي عبد الغفار شعير & 0 \\
\hline أستاذ تصميم طباعة المنسوجات - كلية الفنوذ التطبيقية - جامعة حلوان & أ. د/ علي السيد علي قطب & 7 \\
\hline ملدرس الملابس والنسيج بقسم الاقتصاد المنزلي ـ كلية التربية النوعية - جامعة المنصورة & د/شادية صلاح حسن & $\checkmark$ \\
\hline ملدرس الأشفال الفنية بقسم التربية الفنية ـ كلية التربية النوعية - جامعة المنصورة & د أيمن أحمد دسوقي & $\Lambda$ \\
\hline ملرس الأشفال الفنية بقسم التربية الفنية ـ كلية التربية النوعية - جامعة المنصورة & 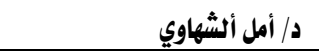 & 9 \\
\hline ملرس الأشفال الفنية بقسم التربية الفنية ـ كلية التربية النوعية - جامعة المنصورة & 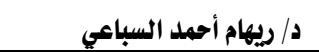 & 1. \\
\hline
\end{tabular}

